\title{
Hardness and Case Depth Analysis Through Optimization Techniques in Surface Hardening Processes
}

\author{
K. Palaniradja*, N. Alagumurthi and V. Soundararajan \\ Department of Mechanical Engineering, Pondicherry Engineering College, Pondicherry - 605 014, India
}

\begin{abstract}
Surface engineering and surface engineered materials find wide applications in engineering industries in recent years. Inconsistency in hardness and case depth has resulted in the further optimization of the process variables involved in surface hardening. In the present study, the following operating parameters viz. preheating, carbon potential, holding position, furnace temperature, carburising time, quenching medium, quenching temperature, quenching time, tempering temperature and tempering time were taken for optimization using the Taguchi and Factorial design of experiment concepts. From the experiments and optimization analysis conducted on EN29 and EN34 materials it was observed that furnace temperature and quenching time had equal influence in obtaining a better surface integrity of the case hardened components using gas carburizing. Preheating before gas carburizing further enhanced the surface hardness and the depth of hardness. In the case of induction hardening process, power potential played a vital role in optimizing the surface hardness and the depth of hardness.
\end{abstract}

Keywords: Pinion, hardness, case depth, taguchi techniques, optimization, process variables.

\section{INTRODUCTION}

Changing demands of dynamic market place have improved and increased the commitment to quality consciousness. All over the world, companies are developing quality management systems like ISO 9001-2000 and investing in total quality [1]. One of the critical requirements for the ISO 9001-2000 is adequate control over process parameters. An auditing report of the ISO indicates that the majority of the heat treatment processes in industries present improper application of process variables and inadequate control over the process parameters [2]. Adequate control of process variables is possible if the level at which each of the parameters has to be maintained. Optimization is one of the approaches that help in finding out the right level or value of the parameters that have to be maintained for obtaining quality output. Determination of optimum parameters lies in the proper selection and introduction of suitable design of experiment at the earliest stage of the process and product development cycles so as to result in the quality and productivity improvement with cost effectiveness [3].

Investigations indicate that in surface hardening processes Heat treatment temperature, rate of heating and cooling, heat treatment period, Quenching media and temperature [4], Post heat treatment and pre-heat treatment processes are the major influential parameters, which affect the quality of the part surface hardened. This paper deals with the optimization studies conducted to evaluate the effect of various process variables in Gas Carburizing and Induction Hardening on the attainable Hardness and Case depth [5].

*Address correspondence to this author at the Department of Mechanical Engineering, Pondicherry Engineering College, Pondicherry-605014, India; Tel: 91413 2655281-287, Ext. 252,259; Fax: 91413 2655101; E-mail: palaniradja72@rediffmail.com
In this study, Taguchi's Design of Experiment concept has been used for the optimization of the process variables of Gas Carburizing process and Factorial design of Experiment for the optimization of process variables of Induction Hardening process. Taguchi's L27 orthogonal array and $3^{3}$ Factorial array have been adopted to conduct experiments in Gas Carburizing and Induction Hardening processes respectively.

Optimum heat treatment conditions have been arrived by employing higher hardness cum case depth are better as the strategies. The secondary objectives of identifying the major influential variables on Hardness and Case depth have also been achieved.

\section{GAS CARBURIZING PROCESS VARIABLES OPTIMIZATION USING TAGUCHI'S METHOD}

In this study, Taguchi's L27 orthogonal array of Design of Experiment is used for the optimization of process variables of Gas carburizing process to improve the surface hardness and case depth of a Case hardened component. All these experiments were carried out by Repetition Method. Two different optimization analyses (Response Graph Analysis and Signal to noise Ratio analysis) have been done on the materials selected for the study. The materials used were EN 29 and EN 34. Experiments have been conducted on the machined component pinion of steering wheel assembly.

The normal procedure followed in converting the raw material into a finished product is shown in Fig. (1).

\section{HARDNESS OF PINION}

Hardness of a material is generally defined as resistance to permanent indentation under static or dynamic loads. Engineering materials are subjected to various applications where the load conditions and functional requirements may vary widely [6]. 
Raw Material selection

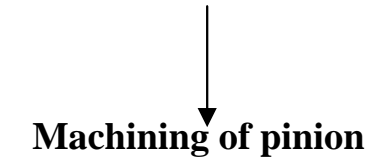

\section{Raw Material}

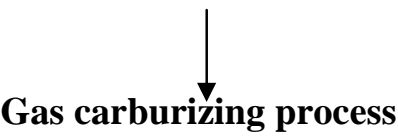

$+$

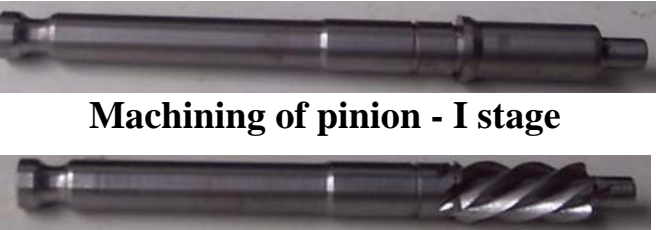

Machining of pinion - II stage

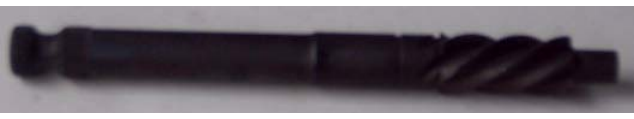

Gas carburized component
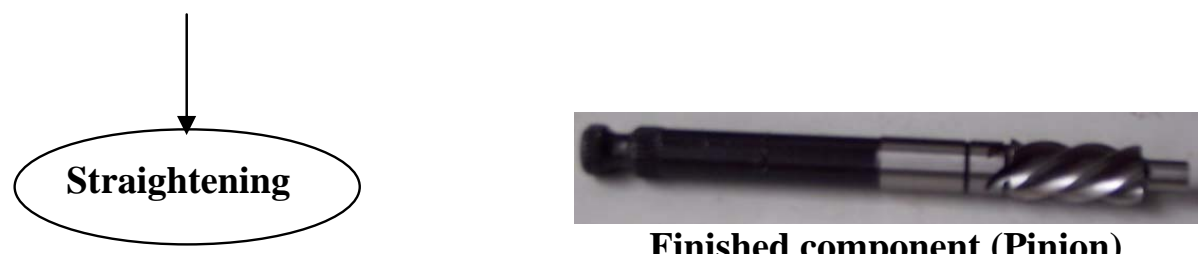

Finished component (Pinion)

Fig. (1). Sequence of operations in gas carburising process.

In automobiles, power steering is an important assembly in which Rack and pinion are the major components subjected to twisting load. In order to improve the wear resistance characteristics and have high reliability, the components (Rack and Pinion) are subjected to case hardening.

The major problem in case hardening is inconsistency in hardness and case depth obtained. The magnitude of hardness depends on the process variables of any surface hardening process. Hence, in the present research, process variable optimization study has been carried for obtaining higher surface hardness on the pinion material (Fig. 2) used in the power steering assembly of the automobile.

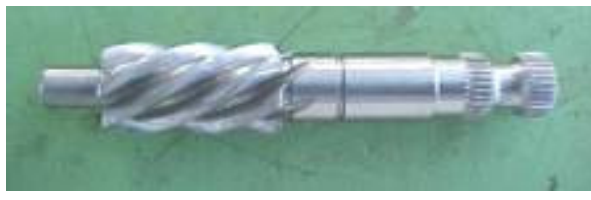

Before Carburizing

\subsection{Hardness Optimization - Response Graph Method}

Response graph method gives the output of interest to be optimized i.e., minimize, maximize, targeted, etc. The output can be more that one and also it can be quantitative or qualitative $[7,8]$. The conditions underwhich gas carburizing experiments have conducted are given in Table 1. Gas carburizing of selected materials have been done in a Unitherm Gas Carburizing Furnace (Fig. 3) where Methanol along with Acetone is used as carburizing medium. The specifications of Gas carburizing furnace and operating conditions with range are given in Table 2 . The test results are reported in Tables $\mathbf{3}$ and $\mathbf{4}$.

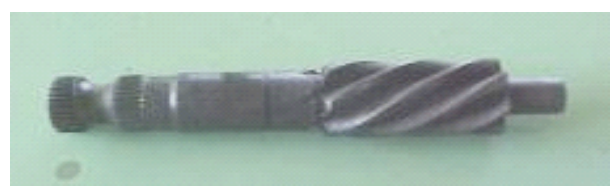

After Carburizing

Fig. (2). Pinion used in the power steering assembly of the automobile.

Table 1. Gas Carburizing-Operating Conditions

\begin{tabular}{|c|c|c|c|c|c|}
\hline S. No. & Factors & Notation & Level 1 & Level 2 & Level 3 \\
\hline \hline 1 & Furnace temperature & A & $870^{\circ} \mathrm{C}$ & $910^{\circ} \mathrm{C}$ & $940^{\circ} \mathrm{C}$ \\
\hline 2 & Quenching Time & B & 60 minutes & 90 minutes & 120 minutes \\
\hline 3 & Tempering Temperature & C & $150^{\circ} \mathrm{C}$ & $200^{\circ} \mathrm{C}$ & 120 minutes \\
\hline 4 & Tempering Time & D & 80 minutes & 100 minutes & $150^{\circ} \mathrm{C}$ \\
\hline 5 & Preheating & E & No preheating & No preheating \\
\hline
\end{tabular}




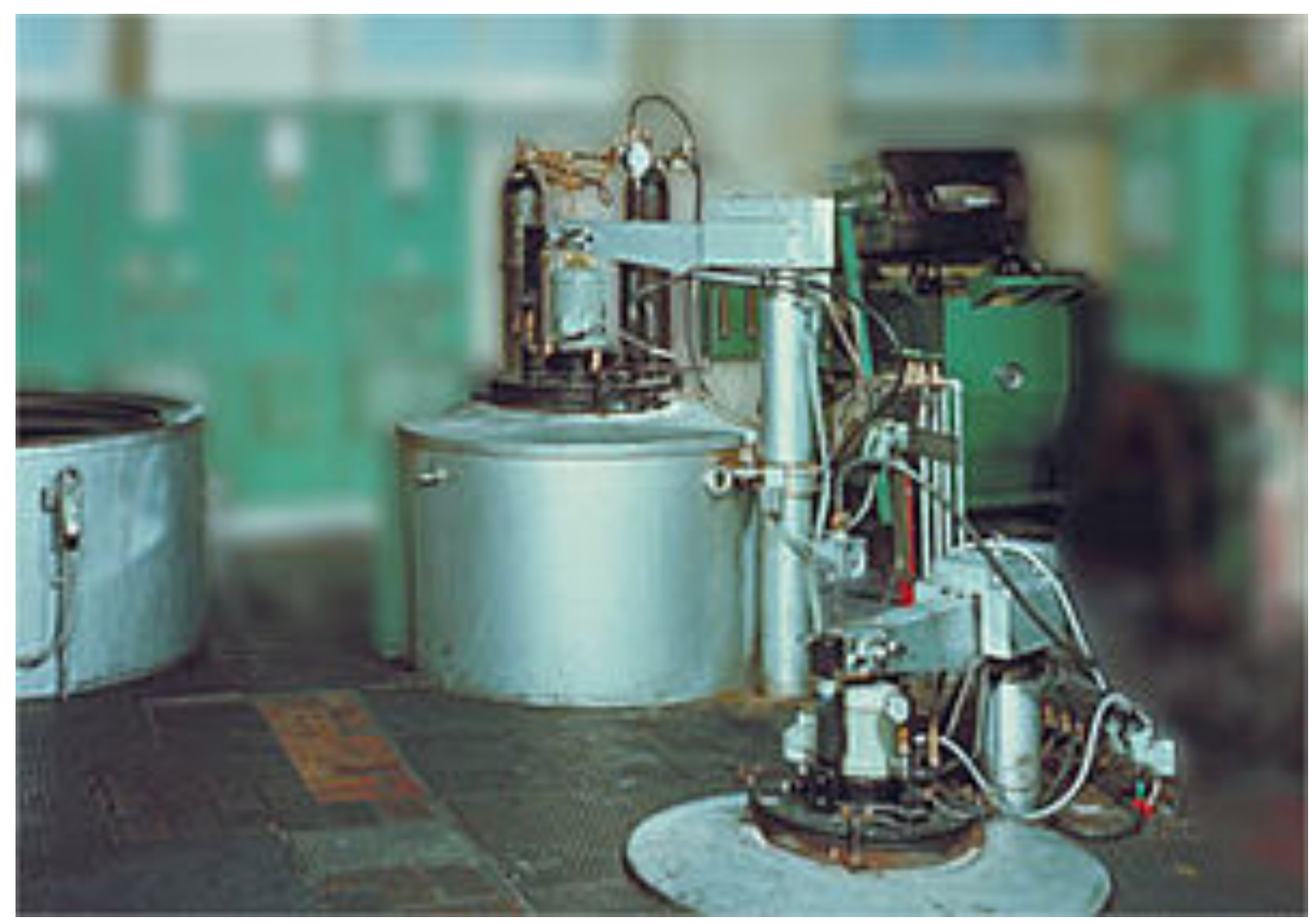

Fig. (3). Gas carburizing furnace.

The experiments have been conducted based on L27 orthogonal array system proposed in Taguchi's mixed level series DOE with interactions as given below:

i) Furnace Temperature $v s$ Quenching time $(\mathrm{AxB})$

ii) Furnace Temperature $v s$ Tempering Temperature (AxC)

Table 2. Specifications and Operating Conditions of Gas Carburizing

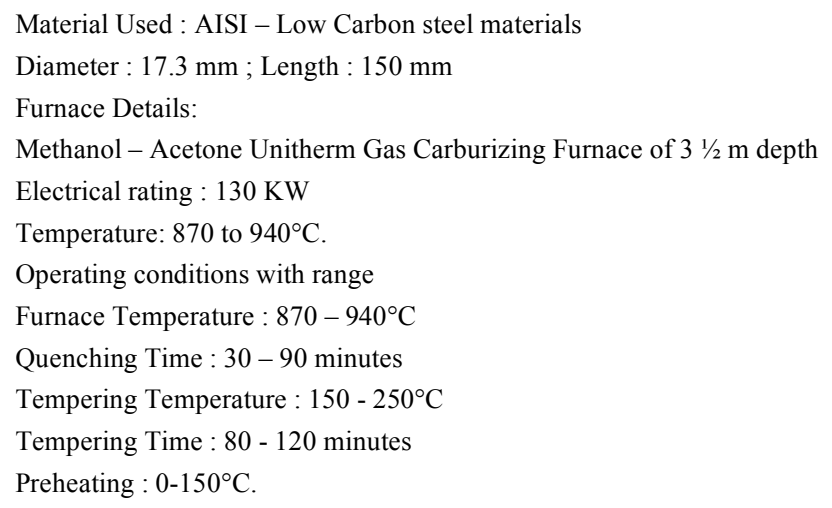

From the experimental result, the average effects of process variables under consideration on the obtainable surface hardness have been calculated and the same are presented in Table 5.

The sample calculation for Average effect of Process variables on surface hardness is given below.
Variable: Furnace temperature, Variable level - Level 1, Material: EN 29 (Table 3).

Average effect $=(77+77.5+78.5+79.5+80.5+77+79.5+$ $78.5+77.5) / 9=78.39$ HRA

Response graphs shown in Fig. (4a-e) are drawn using the values in Table 5 .

\subsubsection{Influence of Process Variables on Hardness}

ANOVA analysis is carried out to determine the influence of main variables on surface hardness and also to determine the percentage contributions of each variable. Table 6 shows the results of percentage contribution of each variable.

\subsubsection{Model Calculation for EN 29}

Correction factor, C.F $=\left[\sum y i\right]^{2} /$ Number of Experiments

$$
=[77+77.5+\ldots . .79]^{2} / 27=168823.14
$$

Total sum of squares, $=\sum y i^{2}-\mathrm{C} . \mathrm{F}=168866-$

$$
\text { SST } \quad 168823.14=42.85
$$

Sum of Squares of Variables,

$$
\begin{aligned}
\text { Variable A, SSA } & =\left[\sum y 1^{2} / 9+\sum y 2^{2} / 9+\sum y 3{ }^{2} / 9\right]-\text { C.F } \\
& =[55303.36+56406.25+57121]-\text { C.F } \\
& =168830.61-168823.14 \\
& =7.47
\end{aligned}
$$

Percentage contribution of each variable, $\mathrm{A} \quad=(\mathrm{SSA} / \mathrm{SST}) * 100$ 
Table 3. Orthogonal Array for Gas Carburizing with Test Results and S/N Ratio Material: EN 29 (Surface Hardness Optimization)

\begin{tabular}{|c|c|c|c|c|c|c|c|c|c|}
\hline \multirow{2}{*}{ S. No. } & \multirow{2}{*}{$\mathbf{A}$} & \multirow{2}{*}{ B } & \multirow{2}{*}{$\mathrm{C}$} & \multirow{2}{*}{ D } & \multirow{2}{*}{$\mathbf{E}$} & \multicolumn{2}{|c|}{ Hardness in HRA } & \multirow{2}{*}{$\begin{array}{c}\text { Average HRA } \\
\text { Value }\end{array}$} & \multirow{2}{*}{$\begin{array}{c}\text { S/N } \\
\text { for HRA }\end{array}$} \\
\hline & & & & & & Trial 1 & Trial 2 & & \\
\hline 1 & 870 & 60 & 150 & 80 & NO & 77 & 77 & 77 & 43.750 \\
\hline 2 & 870 & 60 & 200 & 100 & 150 & 77 & 78 & 77.5 & 43.806 \\
\hline 3 & 870 & 60 & 250 & 120 & NO & 77 & 80 & 78.5 & 43.919 \\
\hline 4 & 870 & 90 & 150 & 100 & 150 & 78 & 81 & 79.5 & 44.029 \\
\hline 5 & 870 & 90 & 200 & 120 & $\mathrm{NO}$ & 79 & 82 & 80.5 & 44.138 \\
\hline 6 & 870 & 90 & 250 & 80 & NO & 77 & 77 & 77 & 43.750 \\
\hline 7 & 870 & 120 & 150 & 120 & NO & 79 & 80 & 79.5 & 44.028 \\
\hline 8 & 870 & 120 & 200 & 80 & NO & 78 & 79 & 78.5 & 43.918 \\
\hline 9 & 870 & 120 & 250 & 100 & 150 & 77 & 78 & 77.5 & 43.806 \\
\hline 10 & 910 & 60 & 150 & 80 & 150 & 79 & 79 & 79 & 43.973 \\
\hline 11 & 910 & 60 & 200 & 100 & $\mathrm{NO}$ & 80 & 78 & 79 & 43.973 \\
\hline 12 & 910 & 60 & 250 & 120 & $\mathrm{NO}$ & 81 & 80 & 80.5 & 44.136 \\
\hline 13 & 910 & 90 & 150 & 100 & $\mathrm{NO}$ & 81 & 80 & 80.5 & 44.136 \\
\hline 14 & 910 & 90 & 200 & 120 & $\mathrm{NO}$ & 81 & 80 & 80.5 & 44.136 \\
\hline 15 & 910 & 90 & 250 & 80 & 150 & 80 & 79 & 79.5 & 44.028 \\
\hline 16 & 910 & 120 & 150 & 120 & NO & 79 & 78 & 78.5 & 43.918 \\
\hline 17 & 910 & 120 & 200 & 80 & 150 & 78 & 78 & 78 & 43.862 \\
\hline 18 & 910 & 120 & 250 & 100 & $\mathrm{NO}$ & 77 & 77 & 77 & 43.750 \\
\hline 19 & 940 & 60 & 150 & 80 & $\mathrm{NO}$ & 79 & 78 & 78.5 & 43.918 \\
\hline 20 & 940 & 60 & 200 & 100 & $\mathrm{NO}$ & 79 & 77 & 78 & 43.863 \\
\hline 21 & 940 & 60 & 250 & 120 & 150 & 81 & 78 & 79.5 & 44.029 \\
\hline 22 & 940 & 90 & 150 & 100 & NO & 82 & 80 & 81 & 44.190 \\
\hline 23 & 940 & 90 & 200 & 120 & 150 & 82 & 81 & 81.5 & 44.243 \\
\hline 24 & 940 & 90 & 250 & 80 & $\mathrm{NO}$ & 81 & 78 & 79.5 & 44.029 \\
\hline 25 & 940 & 120 & 150 & 120 & 150 & 80 & 79 & 79.5 & 44.028 \\
\hline 26 & 940 & 120 & 200 & 80 & $\mathrm{NO}$ & 82 & 79 & 80.5 & 44.138 \\
\hline 27 & 940 & 120 & 250 & 100 & NO & 80 & 78 & 79 & 43.973 \\
\hline
\end{tabular}

$$
=(7.47 / 42.85) * 100=17.43 \%
$$

In the same way the percentage contribution of other variables are calculated.

Total contribution of variables, $(\mathrm{A}+\mathrm{B}+\mathrm{C}+\mathrm{D}+\mathrm{E}+\mathrm{AxB}+\mathrm{AxC})$

$$
\begin{aligned}
& =(17.43+18.21+4.34+7.94+10.19+25.43+3.98) \\
& =87.52 \%
\end{aligned}
$$

$\therefore$ Error $=12.48 \%$
Optimum set of variables for surface hardness are found by adopting the higher is better strategy. The results are given in Table 7 .

\subsection{Prediction of Mean Response - Surface Hardness}

From Taguchis' methodology, equation (1) can be used to predict the surface hardness obtainable.

$\beta=\mathrm{T}+\left(\mathrm{HA}_{\mathrm{opt}}-\mathrm{T}\right)+\left(\mathrm{HB}_{\mathrm{opt}}-\mathrm{T}\right)+\left(\mathrm{HC}_{\mathrm{opt}}-\mathrm{T}\right)+\left(\mathrm{HD}_{\mathrm{opt}}-\mathrm{T}\right)+$ $\left(\mathrm{HE}_{\mathrm{opt}}-\mathrm{T}\right)$ 
where,

$\beta$-predicted mean response

T-mean of all observed hardness values;

$\mathrm{HA}_{\text {opt}}, \mathrm{HB}_{\mathrm{opt}}$ HCopt $\mathrm{HD}_{\mathrm{opt}}$ and $\mathrm{HE}_{\mathrm{opt}}-$ Hardness values obtained at optimum process variable condition.

\subsubsection{Model Calculation for EN 29 Material}

$\mathrm{T}=\{(77+77.5+78.5+79.5+80.5+77+79.5+78.5+77.5+79+80.5+$ $80.5+80.5+79.5+78.5+78+77+78.5+78+79.5+81+79.5+79.5+$ $80.5+79)\} / 27$

(from Table 3 )

$\mathrm{T}=79.0741$
$\mathrm{HA}_{\text {opt }}=79.66667$

$\mathrm{HB}_{\mathrm{opt}}=79.944$

$\mathrm{HC}_{\mathrm{opt}}=79.3333$

From Table 5

$\mathrm{HD}_{\mathrm{opt}}=79.830$

$\mathrm{HE}_{\mathrm{opt}}=79.056$

$\beta$ (Surface hardness $)=79.0741+(79.66667-79.0741)+$ $(79.944-79.0741)+(79.3333-79.0741)+(79.830$ $79.0741)+(79.056-79.0741)=81.5336 \mathrm{HRA}$

Similarly, for EN 34 the predicted mean response = 80.7802HRA optimum surface hardness value, for EN 29 is 81.5336HRA and for EN 34 is $80.7802 \mathrm{HRA}$.

Table 4. Orthogonal Array for Gas Carburizing with Test Results and S/N Ratio Material: EN 34 (Surface Hardness Optimization)

\begin{tabular}{|c|c|c|c|c|c|c|c|c|c|}
\hline \multirow{2}{*}{ S. No. } & \multirow{2}{*}{$\mathbf{A}$} & \multirow{2}{*}{ B } & \multirow{2}{*}{$\mathrm{C}$} & \multirow{2}{*}{ D } & \multirow{2}{*}{$\mathbf{E}$} & \multicolumn{2}{|c|}{ Hardness in HRA } & \multirow{2}{*}{$\begin{array}{c}\text { Average HRA } \\
\text { Value }\end{array}$} & \multirow{2}{*}{$\begin{array}{c}\text { S/N for } \\
\text { HRA }\end{array}$} \\
\hline & & & & & & Trial 1 & Trial 2 & & \\
\hline 1 & 870 & 60 & 150 & 80 & $\mathrm{NO}$ & 76 & 76 & 76 & 43.63687 \\
\hline 2 & 870 & 60 & 200 & 100 & 150 & 79 & 79 & 79 & 43.97314 \\
\hline 3 & 870 & 60 & 250 & 120 & NO & 80 & 78 & 79 & 43.97384 \\
\hline 4 & 870 & 90 & 150 & 100 & 150 & 79 & 78 & 78.5 & 43.91817 \\
\hline 5 & 870 & 90 & 200 & 120 & NO & 79 & 78 & 78.5 & 43.91817 \\
\hline 6 & 870 & 90 & 250 & 80 & NO & 78 & 77 & 77.5 & 43.80681 \\
\hline 7 & 870 & 120 & 150 & 120 & NO & 77 & 80 & 78.5 & 43.91958 \\
\hline 8 & 870 & 120 & 200 & 80 & NO & 76 & 81 & 78.5 & 43.9224 \\
\hline 9 & 870 & 120 & 250 & 100 & 150 & 79 & 79 & 79 & 43.97314 \\
\hline 10 & 910 & 60 & 150 & 80 & 150 & 78 & 78 & 78 & 43.86249 \\
\hline 11 & 910 & 60 & 200 & 100 & $\mathrm{NO}$ & 77 & 76 & 76.5 & 43.69401 \\
\hline 12 & 910 & 60 & 250 & 120 & NO & 80 & 78 & 79 & 43.97384 \\
\hline 13 & 910 & 90 & 150 & 100 & NO & 81 & 77 & 80 & 43.97592 \\
\hline 14 & 910 & 90 & 200 & 120 & NO & 80 & 79 & 80 & 44.02811 \\
\hline 15 & 910 & 90 & 250 & 80 & 150 & 78 & 80 & 80 & 43.97384 \\
\hline 16 & 910 & 120 & 150 & 120 & $\mathrm{NO}$ & 78 & 82 & 80 & 44.08511 \\
\hline 17 & 910 & 120 & 200 & 80 & 150 & 77 & 80 & 78.5 & 43.91958 \\
\hline 18 & 910 & 120 & 250 & 100 & NO & 76 & 79 & 77.5 & 43.80826 \\
\hline 19 & 940 & 60 & 150 & 80 & $\mathrm{NO}$ & 78 & 80 & 79 & 43.97384 \\
\hline 20 & 940 & 60 & 200 & 100 & $\mathrm{NO}$ & 79 & 80 & 80 & 44.02811 \\
\hline 21 & 940 & 60 & 250 & 120 & 150 & 80 & 79 & 80 & 44.02811 \\
\hline 22 & 940 & 90 & 150 & 100 & NO & 81 & 79 & 80 & 44.08308 \\
\hline 23 & 940 & 90 & 200 & 120 & 150 & 82 & 79 & 80.5 & 44.13803 \\
\hline 24 & 940 & 90 & 250 & 80 & $\mathrm{NO}$ & 80 & 78 & 79 & 43.97384 \\
\hline 25 & 940 & 120 & 150 & 120 & 150 & 79 & 79 & 79 & 43.97314 \\
\hline 26 & 940 & 120 & 200 & 80 & $\mathrm{NO}$ & 78 & 78 & 78 & 43.86249 \\
\hline 27 & 940 & 120 & 250 & 100 & NO & 77 & 81 & 79 & 43.97592 \\
\hline
\end{tabular}


Table 5. Average Effect of Process Variables on Surface Hardness

\begin{tabular}{|l|c|c|c|c|c|c|}
\hline \multirow{2}{*}{ Variables } & \multicolumn{2}{|c|}{ Level 1 } & \multicolumn{2}{c|}{ Level2 } & \multicolumn{2}{c|}{ Level3 } \\
\cline { 2 - 7 } & EN 29 & EN 34 & EN 29 & EN 34 & EN 29 & EN 34 \\
\hline \hline Furnace temperature & 78.39 & 78.28 & 79.1667 & 78.8333 & $\mathbf{7 9 . 6 6 6 6 7}$ & $\mathbf{7 9 . 3 8 8 8 9}$ \\
\hline Quenching Time & 78.61 & 78.5 & $\mathbf{7 9 . 9 4 4}$ & $\mathbf{7 9 . 3 3 3}$ & 78.67 & 78.67 \\
\hline Tempering Temperature & 79.222 & 78.778 & $\mathbf{7 9 . 3 3 3 3}$ & $\mathbf{7 8 . 8 3 3 3}$ & 78.667 & 78.667 \\
\hline Tempering Time & 78.6 & 78.3 & 78.778 & 78.833 & $\mathbf{7 9 . 8 3}$ & $\mathbf{7 9 . 3 9}$ \\
\hline Preheating & 78.89 & 78.89 & $\mathbf{7 9 . 0 5 6}$ & $\mathbf{7 9 . 1 6 7}$ & - & - \\
\hline
\end{tabular}

(a)

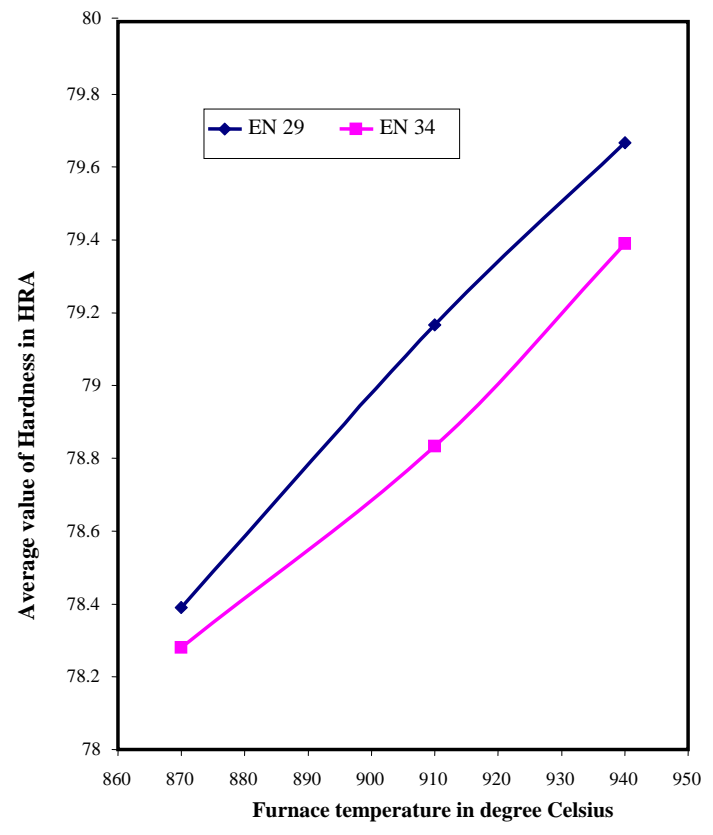

(b)

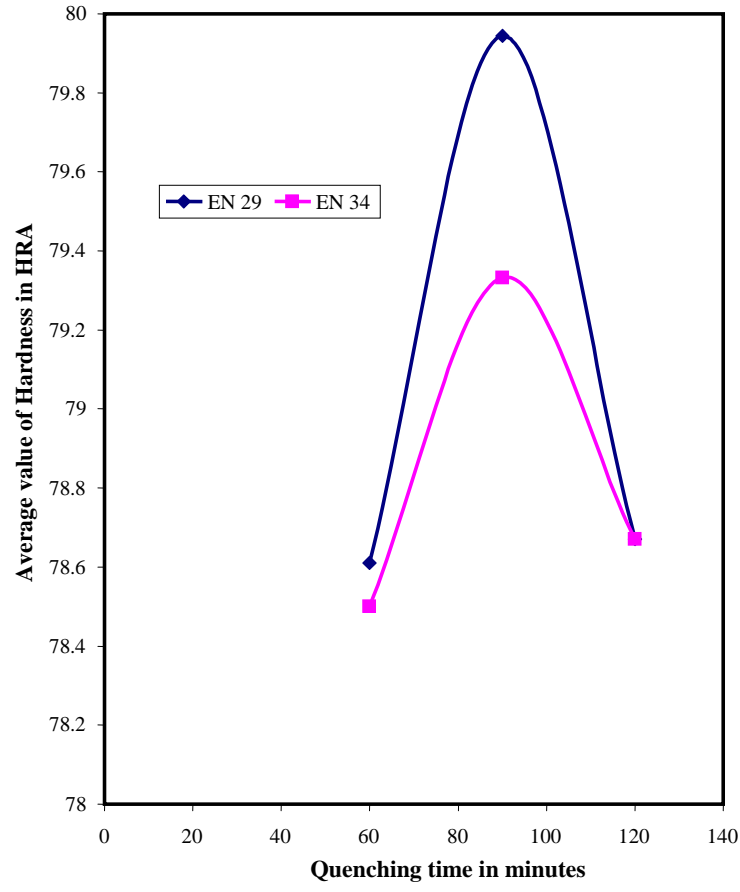

(c)

(Fig. 4) contd.....

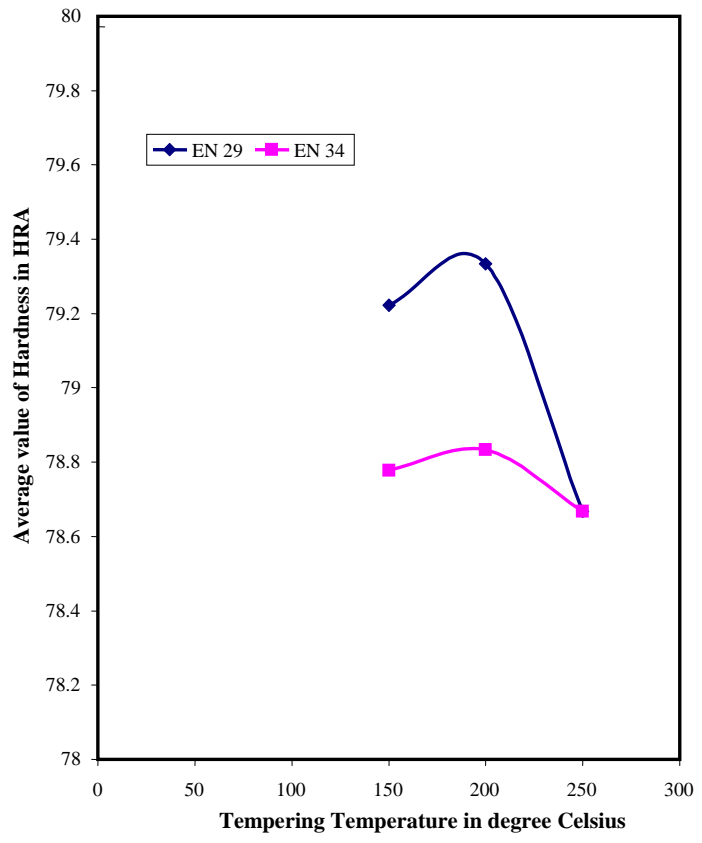

(d)

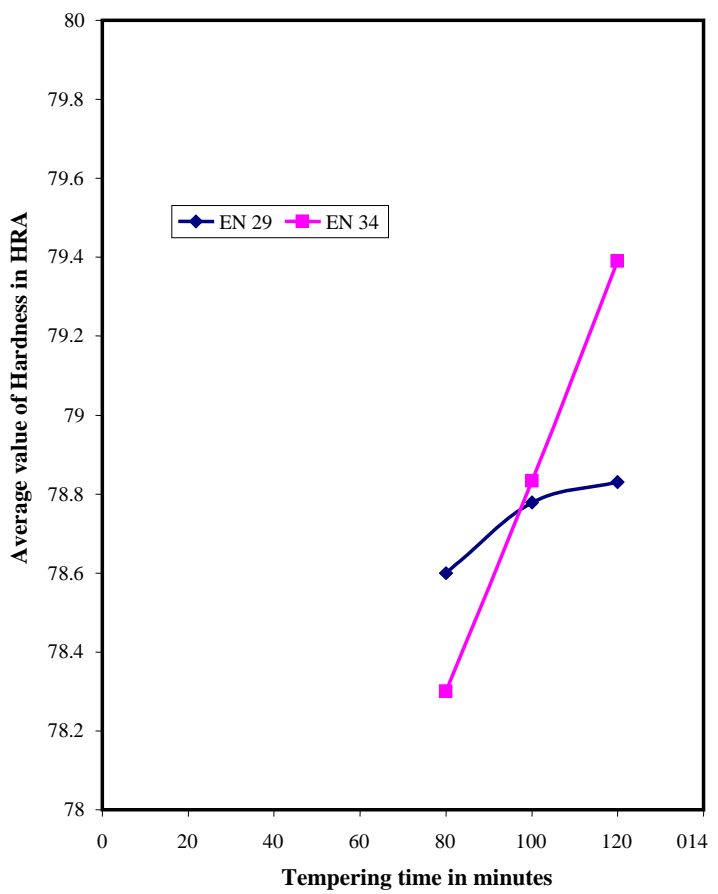


(Fig. 4) contd.....

(e)

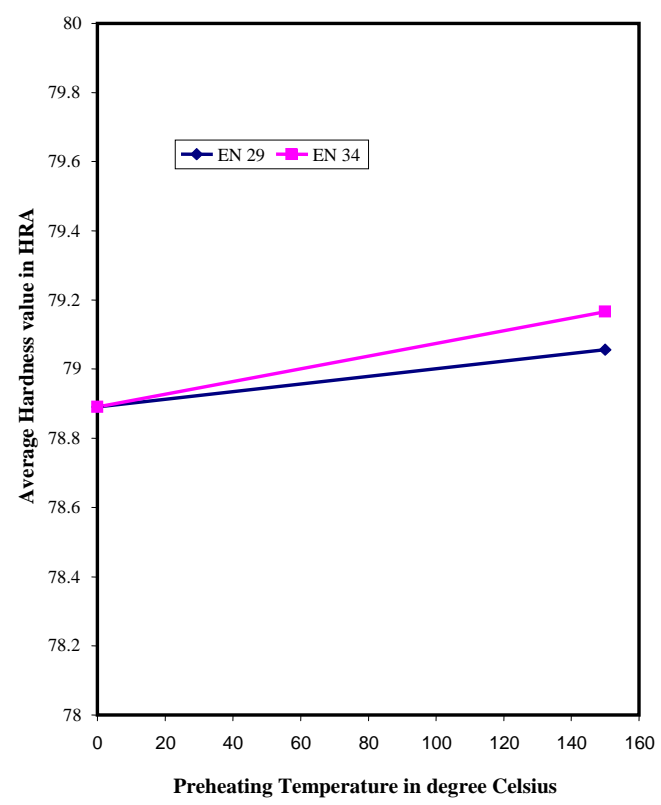

Fig. (4). (a-e) Process variables vs Hardness.

\subsection{Hardness Optimization - Signal to Noise Ratio Method}

Signal noise $(\mathrm{S} / \mathrm{N})$ ratio analysis estimates the effect of noise factors on the performance characteristics. It was developed as a proactive equivalent to the reactive loss function. Signal factors $(\breve{\mathbf{y}})$ are set by the designer to obtain the intended value of the response variable. Noise factors $\left(\mathrm{S}^{2}\right)$ are not controlled or are very expensive or difficult to control (Harisingh and Pradeep Kumar 2004, Davilkar, et al., 2003) [9]. The Gas carburizing conditions adopted in the experimentation are given in Table $\mathbf{1}$, and the test results with $\mathrm{S} / \mathrm{N}$ ratios are reported in Tables $\mathbf{3}$ and $\mathbf{4}$.

$\mathrm{S} / \mathrm{N}$ ratio for maximizing the response factor as the objective (Maximizing the surface hardness) is determined from the equation (2).

$\mathrm{S} / \mathrm{N}=-10 \log _{10}\left[1 / \Sigma \mathrm{yi}^{2} *_{\mathrm{n}}\right]$

where, yi - the experimental response values for the trials, and $\mathrm{n}$ - number of trials.

Optimum condition for surface hardness are found by adopting the higher the $\mathrm{S} / \mathrm{N}$ ratio is better as the strategy and results are given in the Table 7 . The optimum condition result obtained in $\mathrm{S} / \mathrm{N}$ method matches with the optimum result obtained from the response graph analysis.

\subsubsection{Model Calculation for the Material EN 29}

$\mathrm{S} / \mathrm{N}$ ratio for maximizing the Case depth $\left(10^{\text {th }}\right.$ Experiment run)

$\mathrm{S} / \mathrm{N}=-10 \log _{10}\left\{1 /\left(79^{2}+79^{2}\right) * 2\right\}=43.97314$

\section{CASE-DEPTH IN PINION}

Depth of hardness penetration in any surface heat treated material is an important factor in deciding the reliability and life of the part $[10,11]$. Hence, it is necessary to measure the

Table 6. Percentage Contribution of Each Variable on Surface Hardness

\begin{tabular}{|c|c|c|}
\hline \multirow{2}{*}{ Variables } & \multicolumn{2}{|c|}{ Surface Hardness } \\
\cline { 2 - 3 } & $\mathbf{E N ~ 2 9}$ & $\mathbf{1 7 . 7 9 \%}$ \\
\hline \hline Furnace temperature & $\mathbf{1 7 . 4 3 \%}$ & $\mathbf{1 5 . 2 9 \%}$ \\
\hline Quenching Time & $\mathbf{1 8 . 2 1} \%$ & $\mathbf{6 . 3 4 \%}$ \\
\hline Tempering Temperature & $\mathbf{4 . 3 4 \%}$ & $\mathbf{8 . 2 5} \%$ \\
\hline Tempering Time & $\mathbf{7 . 9 4 \%}$ & $\mathbf{1 2 . 3 6 \%}$ \\
\hline Preheating & $\mathbf{1 0 . 1 9 \%}$ & $\mathbf{2 4 . 9 1 \%}$ \\
\hline Furnace Temperature and Tempering Temperature & $\mathbf{2 5 . 4 3 \%}$ & $\mathbf{5 . 2 8} \%$ \\
\hline Error & $\mathbf{3 . 9 8} \%$ & $\mathbf{1 2 . 4 8 \%}$ \\
\hline
\end{tabular}

Table 7. Optimum Conditions for Surface Hardness

\begin{tabular}{|c|c|c|}
\hline \multirow{2}{*}{ Variables } & \multicolumn{2}{|c|}{ Surface Hardness } \\
\hline & EN 29 & EN 34 \\
\hline Furnace temperature & $940^{\circ} \mathrm{C}$ & $940^{\circ} \mathrm{C}$ \\
\hline Quenching Time & 90 minutes & 90 minutes \\
\hline Tempering Temperature & $200^{\circ} \mathrm{C}$ & $200^{\circ} \mathrm{C}$ \\
\hline Tempering Time & 120 minutes & 120 minutes \\
\hline Preheating & $150^{\circ} \mathrm{C}$ & $150^{\circ} \mathrm{C}$ \\
\hline
\end{tabular}


case depth of the hardened layer in the given part. Case depth is defined as "the perpendicular distance from the surface of the metallic material to the point at which the change in hardness, chemical composition or microstructure of the case and core cannot be distinguished" (Rajan, T.V., et al., 1998) [12].

Process variable optimization to obtain the required case depth in the Pinion material (Fig. 5) subjected for Gas carburizing is done both by Response graph analysis and by Signal to Noise ratio analysis. The trials are conducted as per Taguchi’s L27 orthogonal array approach.

\subsection{Case Depth Optimization - Response Graph Method}

The conditions underwhich the Gas carburizing experiments have been conducted to arrive at the optimum process variables are given in Table 1. The test results are reported in Tables 8 and 9.

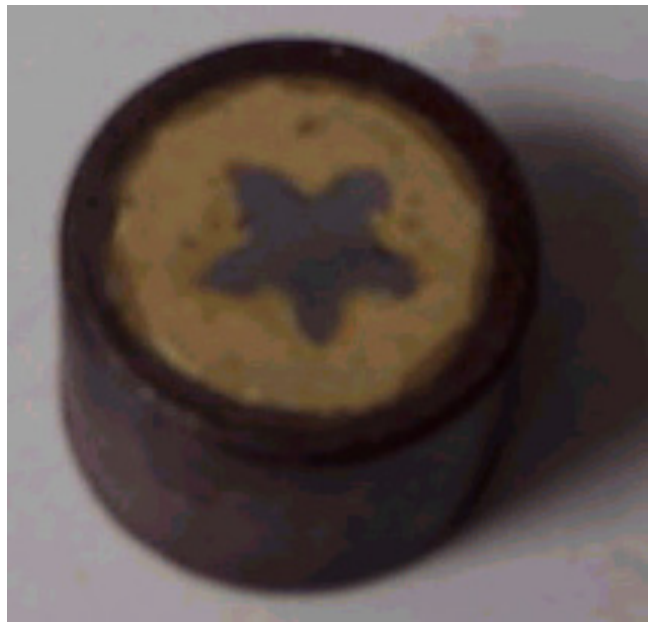

Fig. (5). Specimen of pinion material for case depth analysis.

Table 8. Orthogonal Array of Gas Carburizing with Test Results and S/N Ratio Material: EN 29 (Case -Depth Optimization)

\begin{tabular}{|c|c|c|c|c|c|c|c|c|c|}
\hline \multirow{2}{*}{ S. No. } & \multirow{2}{*}{$\mathbf{A}$} & \multirow{2}{*}{ B } & \multirow{2}{*}{$\mathbf{C}$} & \multirow{2}{*}{ D } & \multirow{2}{*}{$\mathbf{E}$} & \multicolumn{2}{|c|}{ Case Depth in mm } & \multirow{2}{*}{$\begin{array}{l}\text { Average Case } \\
\text { Depth Value }\end{array}$} & \multirow{2}{*}{$\begin{array}{c}\text { S/N for } \\
\text { Case Depth }\end{array}$} \\
\hline & & & & & & Trial 1 & Trial 2 & & \\
\hline 1 & 870 & 60 & 150 & 80 & NO & 0.7 & 0.7 & 0.7 & 2.92 \\
\hline 2 & 870 & 60 & 200 & 100 & 150 & 0.9 & 1 & 0.95 & 5.59 \\
\hline 3 & 870 & 60 & 250 & 120 & NO & 0.7 & 0.8 & 0.75 & 3.54 \\
\hline 4 & 870 & 90 & 150 & 100 & 150 & 0.8 & 0.9 & 0.85 & 4.62 \\
\hline 5 & 870 & 90 & 200 & 120 & NO & 0.9 & 0.9 & 0.9 & 5.11 \\
\hline 6 & 870 & 90 & 250 & 80 & $\mathrm{NO}$ & 1.0 & 0.8 & 0.9 & 5.16 \\
\hline 7 & 870 & 120 & 150 & 120 & NO & 0.8 & 0.9 & 0.85 & 4.62 \\
\hline 8 & 870 & 120 & 200 & 80 & NO & 0.7 & 0.8 & 0.75 & 3.54 \\
\hline 9 & 870 & 120 & 250 & 100 & 150 & 0.8 & 0.8 & 0.8 & 4.08 \\
\hline 10 & 910 & 60 & 150 & 80 & 150 & 0.9 & 1.0 & 0.95 & 5.59 \\
\hline 11 & 910 & 60 & 200 & 100 & $\mathrm{NO}$ & 1.0 & 0.9 & 0.95 & 5.59 \\
\hline 12 & 910 & 60 & 250 & 120 & $\mathrm{NO}$ & 0.8 & 0.8 & 0.8 & 4.08 \\
\hline 13 & 910 & 90 & 150 & 100 & $\mathrm{NO}$ & 0.7 & 0.7 & 0.7 & 2.92 \\
\hline 14 & 910 & 90 & 200 & 120 & NO & 0.6 & 0.6 & 0.6 & 1.58 \\
\hline 15 & 910 & 90 & 250 & 80 & 150 & 0.8 & 0.8 & 0.8 & 4.08 \\
\hline 16 & 910 & 120 & 150 & 120 & $\mathrm{NO}$ & 0.7 & 0.8 & 0.75 & 3.54 \\
\hline 17 & 910 & 120 & 200 & 80 & 150 & 0.7 & 0.7 & 0.7 & 2.92 \\
\hline 18 & 910 & 120 & 250 & 100 & NO & 0.8 & 0.8 & 0.8 & 4.08 \\
\hline 19 & 940 & 60 & 150 & 80 & NO & 0.9 & 0.8 & 0.85 & 4.62 \\
\hline 20 & 940 & 60 & 200 & 100 & $\mathrm{NO}$ & 0.8 & 0.7 & 0.75 & 3.54 \\
\hline 21 & 940 & 60 & 250 & 120 & 150 & 0.7 & 0.6 & 0.65 & 2.3 \\
\hline 22 & 940 & 90 & 150 & 100 & NO & 0.6 & 0.8 & 0.7 & 3.01 \\
\hline 23 & 940 & 90 & 200 & 120 & 150 & 1.0 & 1.0 & 1.0 & 6.02 \\
\hline 24 & 940 & 90 & 250 & 80 & NO & 0.9 & 0.8 & 0.85 & 4.62 \\
\hline 25 & 940 & 120 & 150 & 120 & 150 & 0.9 & 1 & 0.95 & 5.59 \\
\hline 26 & 940 & 120 & 200 & 80 & $\mathrm{NO}$ & 1 & 0.9 & 0.95 & 5.59 \\
\hline 27 & 940 & 120 & 250 & 100 & NO & 0.8 & 0.8 & 0.8 & 4.08 \\
\hline
\end{tabular}


Table 9. Orthogonal Array of Gas Carburizing with Test Results and S/N Ratio Material: EN 34 (Case-Depth Optimization)

\begin{tabular}{|c|c|c|c|c|c|c|c|c|c|}
\hline \multirow{2}{*}{ S.No. } & \multirow{2}{*}{$\mathbf{A}$} & \multirow{2}{*}{ B } & \multirow{2}{*}{$\mathbf{C}$} & \multirow{2}{*}{ D } & \multirow{2}{*}{$\mathbf{E}$} & \multicolumn{2}{|c|}{ Case Depth in mm } & \multirow{2}{*}{$\begin{array}{c}\text { Average Case } \\
\text { Depth Value }\end{array}$} & \multirow{2}{*}{$\begin{array}{c}\text { S/N for } \\
\text { Case Depth }\end{array}$} \\
\hline & & & & & & Trial 1 & Trial 2 & & \\
\hline 1 & 870 & 60 & 150 & 80 & $\mathrm{NO}$ & 0.8 & 0.6 & 0.7 & 3.01 \\
\hline 2 & 870 & 60 & 200 & 100 & 150 & 0.7 & 0.7 & 0.7 & 2.92 \\
\hline 3 & 870 & 60 & 250 & 120 & NO & 0.7 & 0.7 & 0.7 & 2.92 \\
\hline 4 & 870 & 90 & 150 & 100 & 150 & 0.8 & 0.9 & 0.85 & 4.62 \\
\hline 5 & 870 & 90 & 200 & 120 & NO & 0.9 & 0.8 & 0.85 & 4.62 \\
\hline 6 & 870 & 90 & 250 & 80 & NO & 0.6 & 0.7 & 0.65 & 2.3 \\
\hline 7 & 870 & 120 & 150 & 120 & NO & 0.7 & 0.8 & 0.75 & 3.54 \\
\hline 8 & 870 & 120 & 200 & 80 & NO & 0.8 & 0.9 & 0.85 & 4.62 \\
\hline 9 & 870 & 120 & 250 & 100 & 150 & 0.8 & 0.9 & 0.85 & 4.62 \\
\hline 10 & 910 & 60 & 150 & 80 & 150 & 0.8 & 0.8 & 0.8 & 4.08 \\
\hline 11 & 910 & 60 & 200 & 100 & NO & 0.8 & 0.8 & 0.8 & 4.08 \\
\hline 12 & 910 & 60 & 250 & 120 & NO & 0.8 & 0.8 & 0.8 & 4.08 \\
\hline 13 & 910 & 90 & 150 & 100 & NO & 0.8 & 0.7 & 0.75 & 3.54 \\
\hline 14 & 910 & 90 & 200 & 120 & NO & 0.9 & 0.8 & 0.85 & 4.62 \\
\hline 15 & 910 & 90 & 250 & 80 & 150 & 0.9 & 0.8 & 0.85 & 4.62 \\
\hline 16 & 910 & 120 & 150 & 120 & NO & 0.8 & 0.7 & 0.75 & 3.54 \\
\hline 17 & 910 & 120 & 200 & 80 & 150 & 0.7 & 0.6 & 0.65 & 2.3 \\
\hline 18 & 910 & 120 & 250 & 100 & NO & 0.7 & 0.8 & 0.75 & 3.54 \\
\hline 19 & 940 & 60 & 150 & 80 & NO & 0.8 & 0.8 & 0.8 & 4.08 \\
\hline 20 & 940 & 60 & 200 & 100 & NO & 0.8 & 0.8 & 0.8 & 4.08 \\
\hline 21 & 940 & 60 & 250 & 120 & 150 & 0.9 & 0.8 & 0.85 & 4.62 \\
\hline 22 & 940 & 90 & 150 & 100 & NO & 0.8 & 0.8 & 0.8 & 4.08 \\
\hline 23 & 940 & 90 & 200 & 120 & 150 & 1.0 & 0.90 & 0.95 & 5.59 \\
\hline 24 & 940 & 90 & 250 & 80 & NO & 0.9 & 0.8 & 0.85 & 4.62 \\
\hline 25 & 940 & 120 & 150 & 120 & 150 & 0.7 & 0.8 & 0.75 & 3.54 \\
\hline 26 & 940 & 120 & 200 & 80 & NO & 0.9 & 0.8 & 0.85 & 4.62 \\
\hline 27 & 940 & 120 & 250 & 100 & NO & 0.6 & 0.6 & 0.6 & 1.58 \\
\hline
\end{tabular}

The average effects of main factors on case depth are given in Table $\mathbf{1 0}$ for the materials EN 29 and EN 34 respectively.
Response graphs are drawn using Table 10. Fig. (6a-e) (Response graphs) shows the influence of process variables on the case depth for the Materials EN 29 and EN 34.

Table 10. Average Effect of Process Variables on Case Depth

\begin{tabular}{|c|c|c|c|c|c|c|}
\hline Quenching Time & 0.81667 & 0.77 & 0.83889 & 0.8167 & 0.8167 & 0.756 \\
\hline Tempering Temperature & 0.8111 & 0.7722 & 0.86667 & 0.811111 & 0.79444 & 0.8000 \\
\hline Preheating & 0.7778 & 0.7556 & 0.85 & 0.8056 & - & - \\
\hline
\end{tabular}


(Fig. 6) contd......

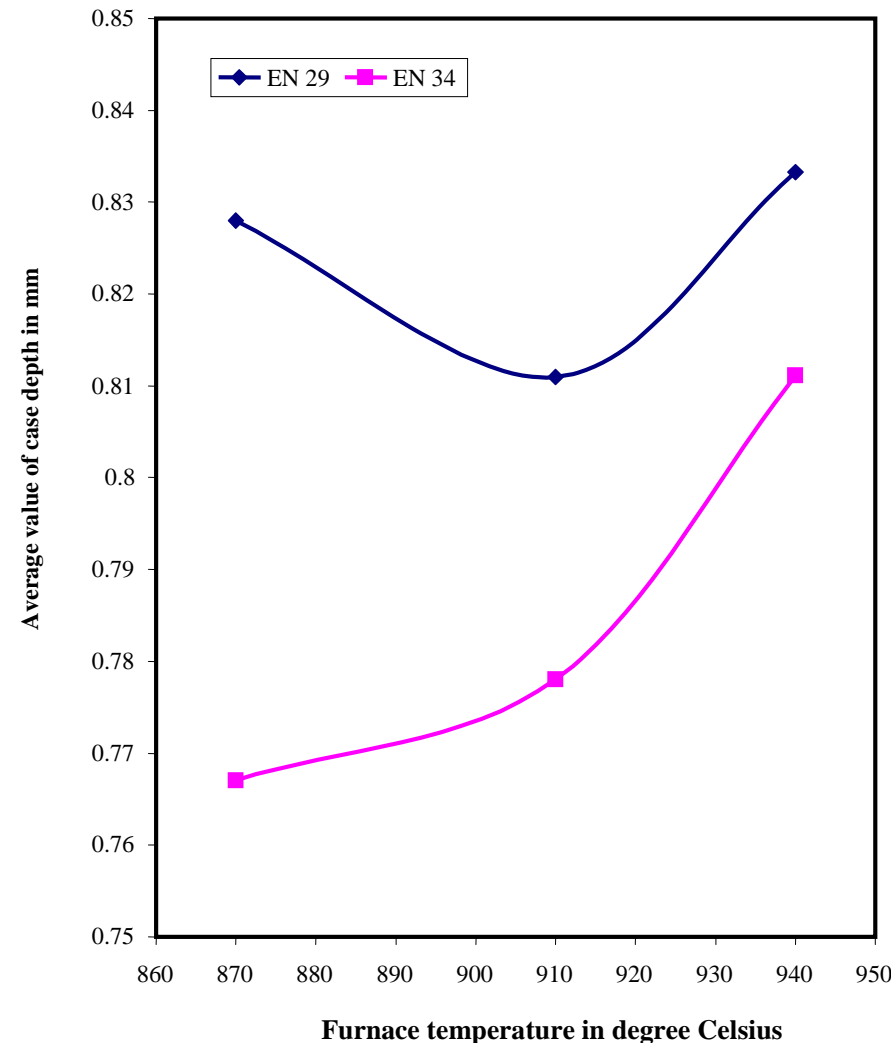

(a)

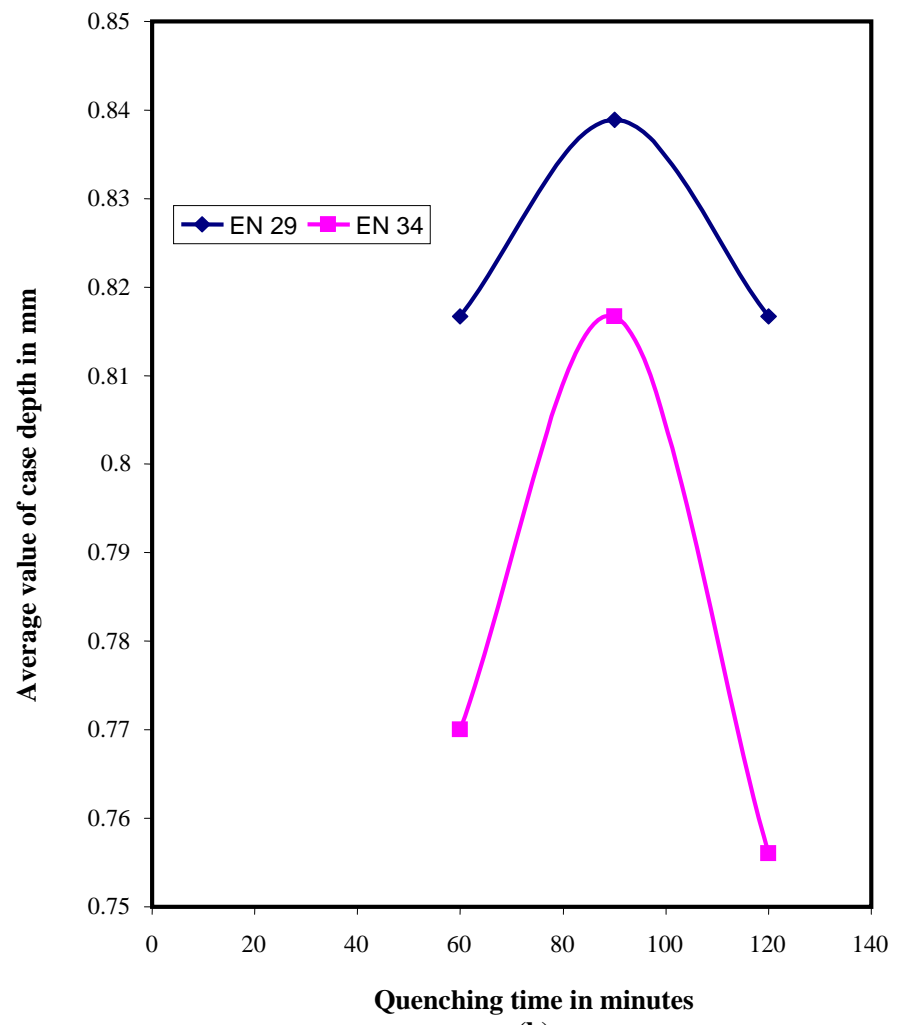

(b)

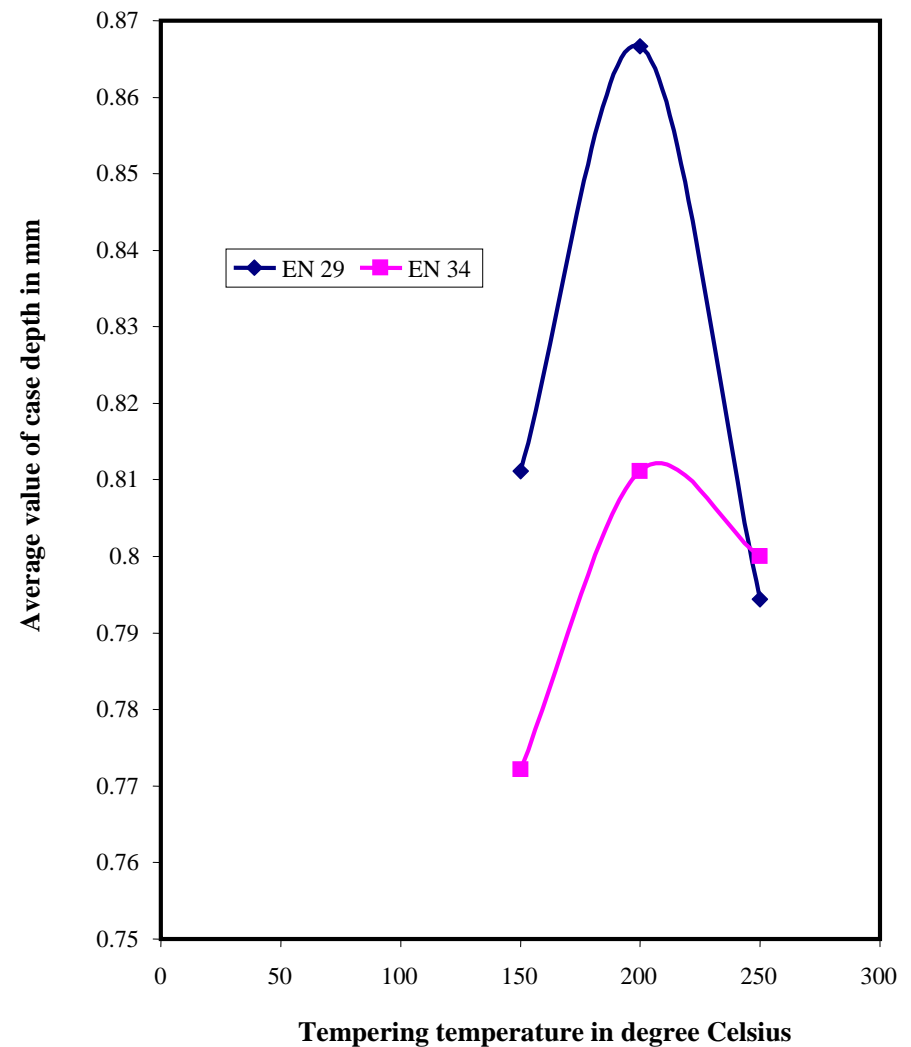

$\square$ F

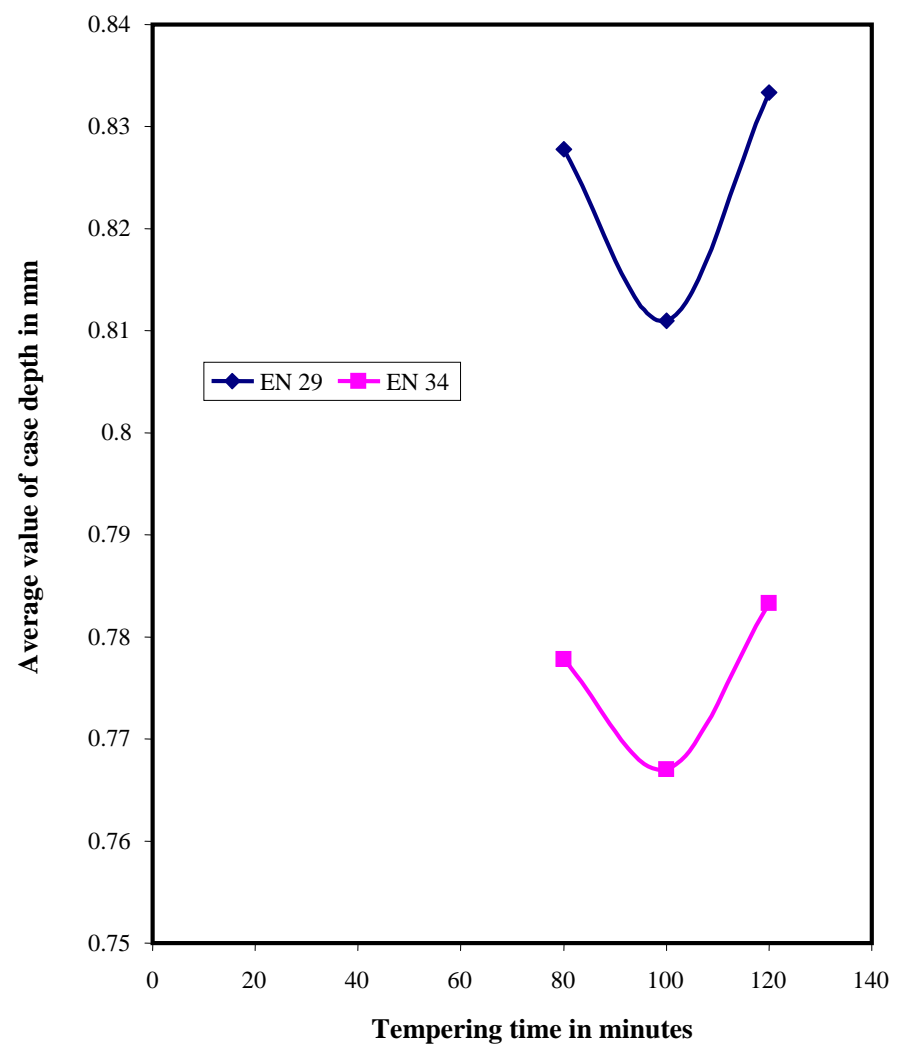

(d) 
(Fig. 6) contd......

(e)

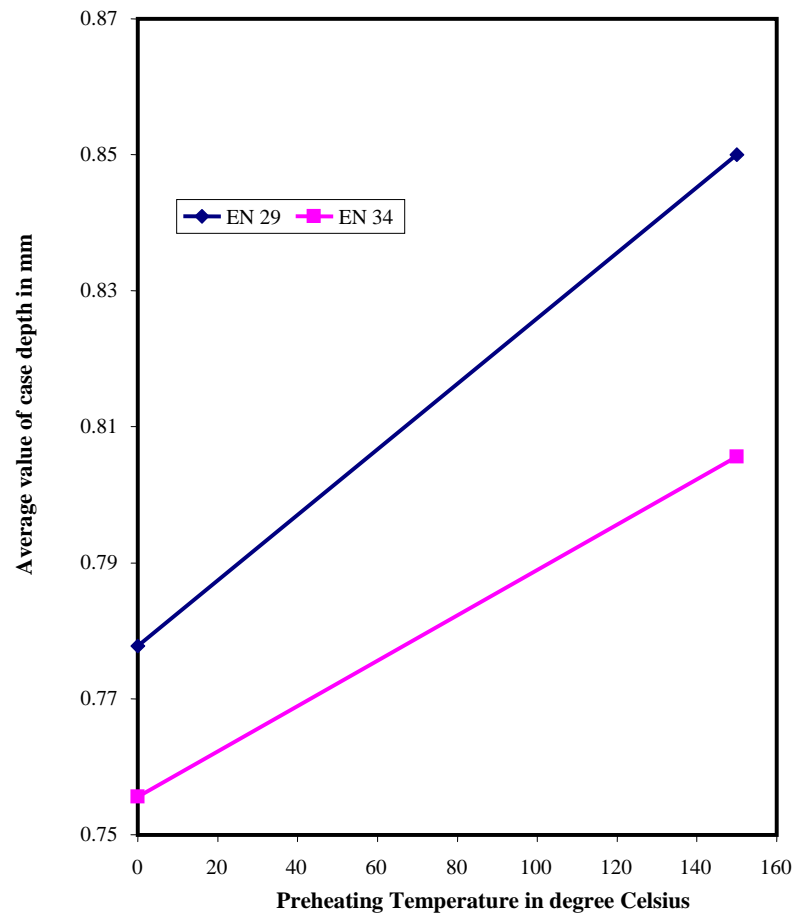

Fig. (6). (a-e) Process variables vs Case-depth.

\subsubsection{Influence of Main Variables on Case Depth}

ANOVA analysis are carried out to determine the influence of main variables on case depth and also to determine the percentage contributions of each variable. Table 11 shows the results of percentage contribution of each variable.

\subsubsection{Model Calculation for EN 29}

Correction factor, C.F $=\left[\sum y i\right]^{2} /$ Number of

$$
\begin{aligned}
& \text { Experiments } \\
= & {[0.7+0.95+\ldots . .0 .8]^{2} / 27=17.925 }
\end{aligned}
$$

Total sum of squares, $\mathrm{SST}=\sum y i^{2}-\mathrm{C} . \mathrm{F}$

$$
=18.215-17.925=0.29
$$

Sum of Squares of variables,

Variable A, SSA

$$
\begin{aligned}
= & {\left[\sum y 1^{2} / 9+\sum y 2^{2 / 9+}\right.} \\
& \left.\sum y 3^{2 / 9}\right]- \text { C.F } \\
= & {[6.166+5.522+6.25]-\text { C.F } } \\
= & 17.938-17.925 \\
= & 0.013
\end{aligned}
$$

Percentage contribution of

Variable, A

$$
\begin{aligned}
& =(\mathrm{SSA} / \mathrm{SST}) * 100 \\
& =(0.013 / 0.29) * 100=4.48 \%
\end{aligned}
$$

In the same way the percentage contribution of other variables are calculated.

Total contribution of variables

$$
\begin{aligned}
& =(\mathrm{A}+\mathrm{B}+\mathrm{C}+\mathrm{D}+\mathrm{E}+\mathrm{AxB}+\mathrm{AxC}) \\
& =(4.48+5.99+9.13+11.28+16.28+29.17+8.18) \\
& =84.51 \%
\end{aligned}
$$

$\therefore$ Error $\quad=12.48 \%$

Table 11. Percentage Contribution of Each Variable on Case Depth

\begin{tabular}{|l|c|c|}
\hline \multirow{2}{*}{ Variables } & \multicolumn{2}{c|}{ Case Depth } \\
\cline { 2 - 3 } & EN 29 & EN 34 \\
\hline \hline Furnace temperature & $\mathbf{4 . 4 8 \%}$ & $\mathbf{5 . 4 3 \%}$ \\
\hline Quenching Time & $\mathbf{5 . 9 9 \%}$ & $\mathbf{7 . 1 4} \%$ \\
\hline Tempering Temperature & $\mathbf{9 . 1 3 \%}$ & $\mathbf{1 1 . 4 1 \%}$ \\
\hline Tempering Time & $\mathbf{1 1 . 2 8 \%}$ & $\mathbf{1 2 . 7 8 \%}$ \\
\hline Preheating & $\mathbf{1 6 . 2 8 \%}$ & $\mathbf{1 5 . 4 9 \%}$ \\
\hline Furnace Temperature and Quenching time & $\mathbf{2 9 . 1 7 \%}$ & $\mathbf{2 8 . 1 8 \%}$ \\
\hline Furnace Temperature and Tempering temperature & $\mathbf{8 . 1 8 \%}$ & $\mathbf{9 . 1 6 \%}$ \\
\hline Error & $\mathbf{1 2 . 4 8 \%}$ & $\mathbf{1 0 . 4 1 \%}$ \\
\hline
\end{tabular}

Optimum conditions for Case depth are found by adopting the higher is better strategy. The results are given in Table 7. It is significant to note that the optimum conditions for hardness and case depth are the same.

\subsection{Prediction of Mean Response - Case Depth}

$\beta=\mathrm{T}+\left(\mathrm{CA}_{\mathrm{opt}}-\mathrm{T}\right)+\left(\mathrm{CB}_{\mathrm{opt}}-\mathrm{T}\right)+\left(\mathrm{CC}_{\mathrm{opt}}-\mathrm{T}\right)+\left(\mathrm{CD}_{\mathrm{opt}}-\mathrm{T}\right)+$ $\left(\mathrm{CE}_{\text {opt }}-\mathrm{T}\right)$

where,

$\beta$-predicted mean response

T-mean of all observed case depth values;

CAopt, CBopt, CCopt, $\mathrm{CD}_{\text {opt }}$, and $\mathrm{CE}_{\text {opt }}$ - Case depth values obtained at optimum process variable conditions

\subsubsection{Model Calculation for EN29 Material}

$\mathrm{T}=\{(0.70+0.95+0.75+0.85+0.90+0.90+0.85+0.75+0.80+0.95+$ $0.95+0.80+0.70+0.60+0.80+0.75+0.70+0.80+0.85+0.75+0.6$ $5+0.70+1.00+0.85+0.95+0.95+0.80)\} / 27$ (from Table 8)

$\mathrm{T}=0.81481$

$\mathrm{CA}_{\mathrm{opt}}=0.8333$

$\left.\mathrm{CB}_{\mathrm{opt}}=0.83889\right\}$

from Table 11

$\mathrm{CC}_{\text {opt }}=0.8667$

$\mathrm{CD}_{\text {opt }}=0.8333$

$\mathrm{CE}_{\text {opt }}=0.85$

$\beta($ Case depth $)=0.81481+(0.8333-0.81481)+$ $(0.83889-0.81481)+(0.8667-0.81481)+$ $(0.8333-0.81481)+(0.85-0.81481)$

$=0.879605 \mathrm{~mm}$ 
Similarly for EN 34 the predicted mean response = $0.96265 \mathrm{~mm}$.

Optimum Case depth value, for EN $29=\mathbf{0 . 9 6 2 6 5} \mathbf{~ m m}$ and for EN $34=\mathbf{0 . 8 9 4 5} \mathbf{~ m m}$.

\subsection{Case Depth Optimization - Signal to Noise Ratio Method}

Gas carburizing conditions adopted in the experimentation are given in Table $\mathbf{1}$, and the test results with $\mathrm{S} / \mathrm{N}$ ratio are given in Tables $\mathbf{8}$ and 9. Optimum condition for Case depth are found by adopting the higher the $\mathrm{S} / \mathrm{N}$ ratio is better as the strategy and results are given in the Table 7. The optimum condition result obtained in $\mathrm{S} / \mathrm{N}$ method matches with the optimum result obtained from the response graph analysis.

\subsubsection{Model Calculation for the Material EN 29}

$\mathrm{S} / \mathrm{N}$ ratio for maximizing the Case depth $\left(13^{\text {th }}\right.$ Experiment run)

$\mathrm{S} / \mathrm{N}=-10 \log _{10}\left\{1 /\left(0.7^{2}+0.7^{2}\right) * 2\right\}=2.92256$

\section{INDUCTION HARDENING PROCESS VARIABLES OPTIMIZATION USING FACTORIAL METHOD}

In this study $3^{3}$ Factorial Design Matrix is used to optimize the process variables for obtaining improved surface integrity of surface hardened components [13]. The experiments are conducted to study the influence of process variables on Surface hardness and Case depth as per Classical DOE. All these trials have been carried out by Randomization method. ANOVA analysis with F-Test has been carried out to determine the influence of each factor and their interactions. Regression analysis is done to develop a modeling equation to predict the hardness [14]. AISI 4340 and AISI 1055 are the materials used in this Induction hardening process experiment. The normal procedure followed in converting the raw material into a finished product is shown in Fig. (7).

\subsection{Hardness Optimization on Rack}

Induction surface hardened low alloyed medium carbon steels are widely used for critical automotive and machine applications such as rack and pinion, propulsion shaft, crankshaft and steering knuckles, which require high surface hardness with low distortion. Rack is a critical component used in the power steering of automobiles. Normally, the rack is surface hardened by Induction hardening to withstand the wear loads. Literatures show that in the case of induction hardening process, the power potential, scan speed (Heating Time) [15]. Quench flow rate and frequency are the major influential variables, which controls the surface hardness, hardness penetration depth (HPD) and level of distortion. The present study demonstrates the optimization of critical process variables involved in the Induction hardening of a Rack material used in the power steering of the automobile [16].

In order to study the influence of process variables on the hardness in the AISI 4340 and AISI 1055 Rack materials, Induction hardening experiments are conducted. Experimental investigations are carried out in Electro magnetic Induction hardening Furnace (Fig. 8). Table 12 shows the details about the operating conditions. The specifications of induction hardening Furnace are given in Table 13. Tables 14 and $\mathbf{1 5}$ shows the Experimental results in the $3^{3}$ Design Matrix for the materials AISI 4340 and AISI 1055 respectively. Tables $\mathbf{1 6}$ and $\mathbf{1 7}$ show the ANOVA with F-Test of the materials AISI 4340 and AISI 1055 respectively.
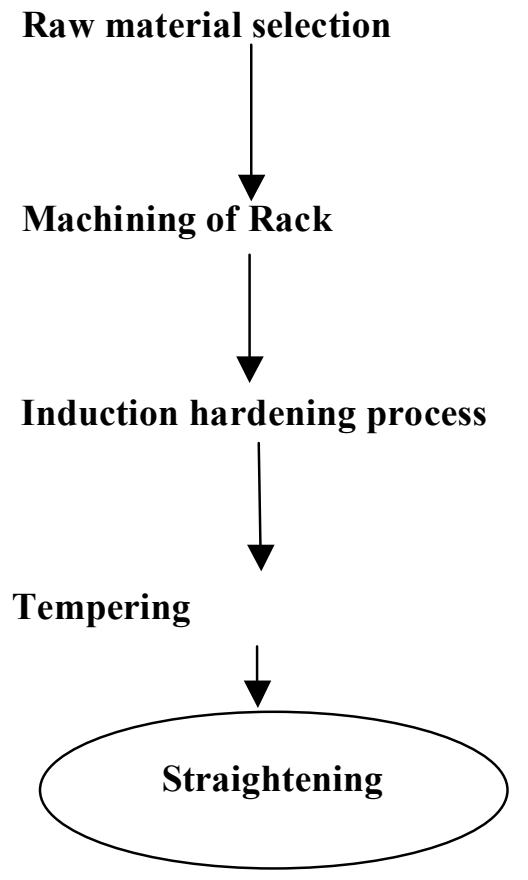

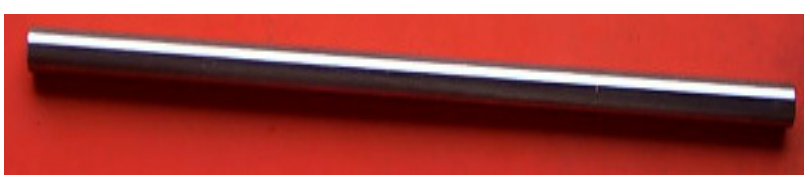

Raw material

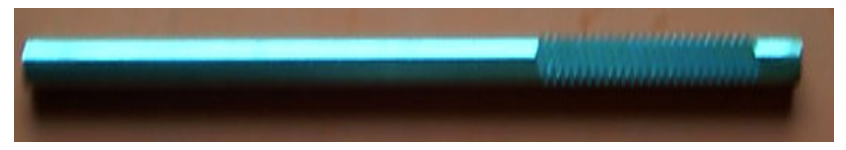

Machined component

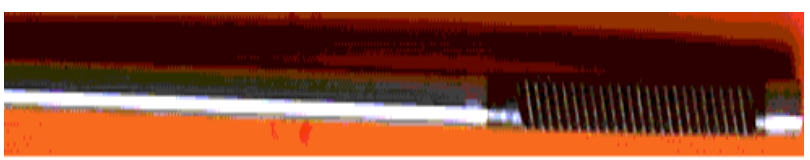

Induction hardened component

Fig. (7). Sequence of operation in induction hardening. 
Table 12. Induction Hardening Operating Conditions

\begin{tabular}{|c|c|c|c|c|c|c|c|c|c|}
\hline \multirow{2}{*}{ S. No. } & \multirow{2}{*}{ Variables } & \multirow{2}{*}{ Unit } & \multirow{2}{*}{ Notation } & \multicolumn{3}{|c|}{ Levels actual } & \multicolumn{4}{|c|}{ Code } \\
\cline { 5 - 11 } & & & & Low & Medium & High & Low & Medium & High \\
\hline \hline 1 & Power potential & $\mathrm{kW} / \mathrm{inch}^{2}$ & $\mathrm{P}$ & 5.5 & 7.05 & 8.5 & $\mathrm{~L} 1$ & $\mathrm{~L} 2$ & $\mathrm{~L} 3$ \\
\hline 2 & Scan speed & $\mathrm{m} / \mathrm{min}$ & $\mathrm{S}$ & 1.34 & 1.72 & 2.14 & $\mathrm{~L} 1$ & $\mathrm{~L} 2$ & $\mathrm{~L} 3$ \\
\hline 3 & Quench flow rate & Litres/min & $\mathrm{Q}$ & 15 & 17.5 & 20 & $\mathrm{~L} 1$ & $\mathrm{~L} 2$ & $\mathrm{~L} 3$ \\
\hline
\end{tabular}

The experiments have been conducted based on $3^{3}$ full factorial DOE.

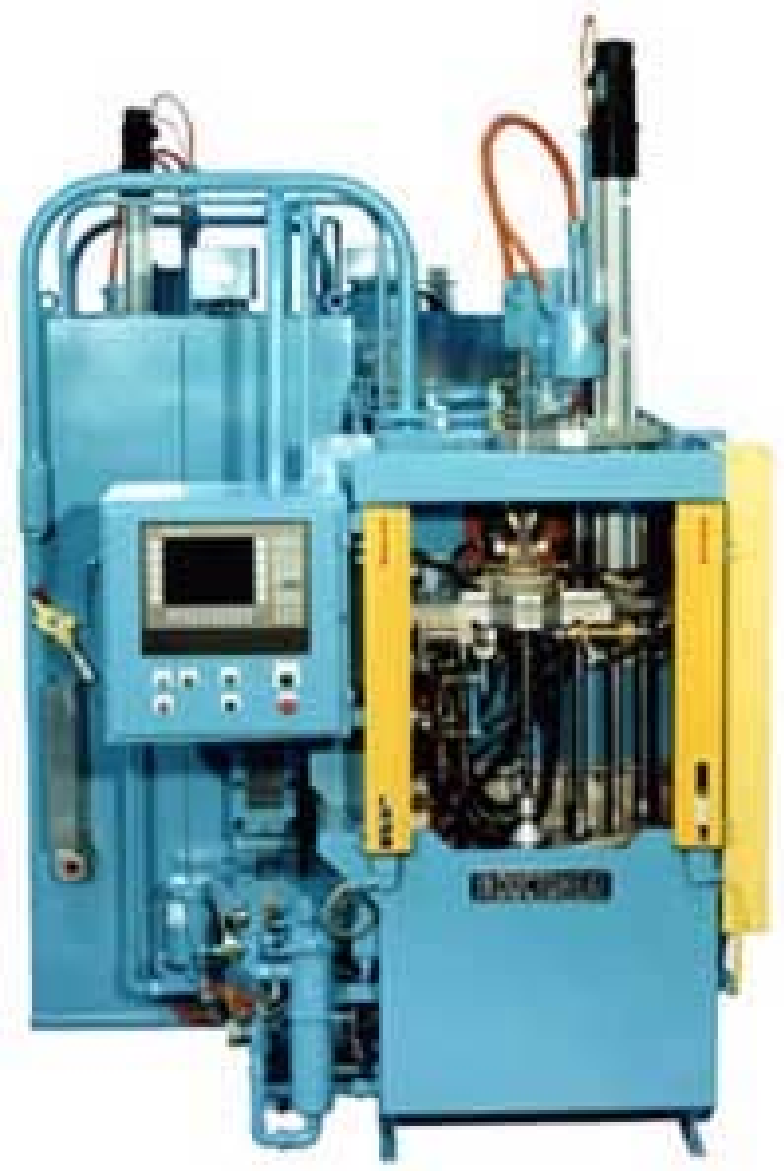

Fig. (8). Induction hardening furnace.

Table 13. Specifications and Operating Conditions of Induction Hardening

\footnotetext{
Material Used : AISI - Medium Carbon steel materials

Diameter : $23 \mathrm{~mm}$; Heating length : $200 \mathrm{~mm}$

Furnace Details:

$440 \mathrm{~V}, 3 \mathrm{~mm}$ coupling distance Inducto Heat induction hardening device

Frequency ; 1000 to 10,000 cycles per second

Temperature: 750 to $800^{\circ} \mathrm{C}$.

Operating conditions with range

Power Potential - $5.5-8.5 \mathrm{~kW} / \mathrm{inch}^{2}$

Scan speed - $1.72-2.5 \mathrm{~m} /$ minutes

Quench Flow rate - 15 - 20 Litres/minutes
}

\subsubsection{Influence of Main Variables on Surface Hardness of Rack Material}

\subsubsection{Model Calculation (AISI 4340)}

Total sum of the run $=(83+81+82+\ldots .63+66+63)=5958$

Number of Treatments $=3$ (3 Factors)

Number of Levels $\quad=3$

Number of replicates $(r)=3$

Total of the observations

under all factor levels $=\mathrm{N}=$ abcr $=3 \times 3 \times 3 \times 3=81$

Correction factor, $(\mathrm{C})=(5958)^{2} / 81$

$$
=438244
$$

Sum of Squares of

Treatment, (SST)

$$
\begin{aligned}
& =\left(83^{2}+81^{2}+82^{2}+\ldots 63^{2}+66^{2}+63^{2}\right) \\
& =(440832)-\mathrm{C} \\
& =2588
\end{aligned}
$$

Sum of Squares of Treatment

$$
\begin{aligned}
\text { with replicates, }\left(\mathrm{SST}_{\mathrm{r}}\right) & =1 / 3\left(246^{2}+249^{2}+\ldots 192^{2}\right) \\
& =1 / 3(1322244)-\mathrm{C} \\
& =2504
\end{aligned}
$$

\begin{tabular}{|c|c|c|c|c|c|c|c|c|c|c|c|}
\hline & \multicolumn{3}{|c|}{$\mathbf{S}$} & & \multicolumn{3}{|c|}{$\mathbf{Q}$} & & \multicolumn{3}{|c|}{$\mathbf{Q}$} \\
\hline 2154 & 729 & 711 & 714 & \multirow{3}{*}{$\mathrm{P}$} & & & & 2034 & 690 & 984 & 660 \\
\hline 1974 & 654 & 660 & 660 & & & & & 1956 & 648 & 654 & 654 \\
\hline 1830 & 651 & 585 & 594 & & & & & 1968 & 669 & 654 & 645 \\
\hline 5958 & 2034 & 1956 & 1968 & 2154 & 723 & 723 & 708 & 5958 & 2007 & 1992 & 1959 \\
\hline \multirow{3}{*}{$\mathrm{P}$} & & & & 1974 & 657 & 660 & 657 & \multirow{3}{*}{$\mathrm{S}$} & & & \\
\hline & & & & 1830 & 627 & 609 & 594 & & & & \\
\hline & & & & 5958 & 2007 & 1992 & 1959 & & & & \\
\hline
\end{tabular}

Sum of Squares of Replicate, (SSR)

$$
\begin{aligned}
& =1 / 27\left(1980^{2}+1989^{2}+1989^{2}\right)-\mathrm{C} \\
& =2 \\
& =\mathrm{SST}_{-} \mathrm{SST}_{\mathrm{r}}-\mathrm{SSR} \\
& =2588-2504-2 \\
& =82
\end{aligned}
$$

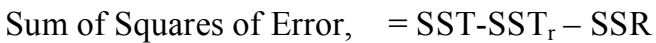


Table 14. $3^{3}$ Design Matrix for Induction Hardening with Test Results Material: AISI 4340 (Surface Hardness)

\begin{tabular}{|c|c|c|c|c|c|c|}
\hline \multirow{2}{*}{ S. No. } & \multirow{2}{*}{$\mathbf{P}$} & \multirow{2}{*}{$\mathbf{S}$} & \multirow{2}{*}{$\mathbf{Q}$} & \multicolumn{3}{|c|}{ Hardness in HRA } \\
\hline & & & & Trial 1 & Trial 2 & Trial 3 \\
\hline 1 & 5.5 & 1.34 & 15 & 83 & 81 & 82 \\
\hline 2 & 5.5 & 1.34 & 17.5 & 84 & 83 & 82 \\
\hline 3 & 5.5 & 1.34 & 20 & 76 & 78 & 80 \\
\hline 4 & 5.5 & 1.72 & 15 & 79 & 80 & 78 \\
\hline 5 & 5.5 & 1.72 & 17.5 & 79 & 81 & 80 \\
\hline 6 & 5.5 & 1.72 & 20 & 76 & 80 & 78 \\
\hline 7 & 5.5 & 2.14 & 15 & 79 & 81 & 80 \\
\hline 8 & 5.5 & 2.14 & 17.5 & 79 & 77 & 78 \\
\hline 9 & 5.5 & 2.14 & 20 & 80 & 81 & 79 \\
\hline 10 & 7.05 & 1.34 & 15 & 74 & 72 & 76 \\
\hline 11 & 7.05 & 1.34 & 17.5 & 69 & 71 & 73 \\
\hline 12 & 7.05 & 1.34 & 20 & 73 & 72 & 74 \\
\hline 13 & 7.05 & 1.72 & 15 & 69 & 71 & 70 \\
\hline 14 & 7.05 & 1.72 & 17.5 & 75 & 75 & 75 \\
\hline 15 & 7.05 & 1.72 & 20 & 76 & 74 & 75 \\
\hline 16 & 7.05 & 2.14 & 15 & 76 & 74 & 75 \\
\hline 17 & 7.05 & 2.14 & 17.5 & 74 & 73 & 75 \\
\hline 18 & 7.05 & 2.14 & 20 & 70 & 72 & 71 \\
\hline 19 & 8.5 & 1.34 & 15 & 75 & 73 & 74 \\
\hline 20 & 8.5 & 1.34 & 17.5 & 74 & 75 & 73 \\
\hline 21 & 8.5 & 1.34 & 20 & 68 & 70 & 69 \\
\hline 22 & 8.5 & 1.72 & 15 & 68 & 66 & 67 \\
\hline 23 & 8.5 & 1.72 & 17.5 & 64 & 63 & 62 \\
\hline 24 & 8.5 & 1.72 & 20 & 65 & 65 & 65 \\
\hline 25 & 8.5 & 2.14 & 15 & 66 & 68 & 70 \\
\hline 26 & 8.5 & 2.14 & 17.5 & 66 & 67 & 65 \\
\hline 27 & 8.5 & 2.14 & 20 & 63 & 66 & 63 \\
\hline
\end{tabular}

\subsubsection{Sum of Squares of Main Effect (P, $S$ and $Q)$}

Sum of Square of Power Potential, SSP = $\left[1 / 27\left(2154^{2}+1974^{2}+1830^{2}\right)\right]-\mathrm{C}=1952$

Sum of Square of Scan Speed, SSS $\left[1 / 27\left(2034^{2}+1956^{2}+1968^{2}\right)\right]-\mathrm{C}=130.66$

Sum of Square of Quench flow rate, SSQ = $\left[1 / 27\left(2007^{2}+1992^{2}+1959^{2}\right)\right]-\mathrm{C}=44.66$

\subsubsection{Two-Way Interactions of Sum of Squares (PS, SQ and $P Q)$}

Sum of Square of Power Potential and Scan Speed $=\left[1 / 9\left(729^{2}+\ldots 594^{2}\right)\right]-\mathrm{C}=177.34$
Sum of Square of Scan Speed and Quench flow rate $=\left[1 / 9\left(690^{2}+\ldots 645^{2}\right)\right]-\mathrm{C}=46.68$

Sum of Square of Power Potential and Quench flow rate $=\left[1 / 9\left(723^{2}+\ldots .594^{2}\right)\right]-\mathrm{C}=33.34$

\subsubsection{Three Way Interactions of Sum of Square (PSQ)}

Sum of Square of Power Potential, Scan speed and

Quench flow rate

$$
\begin{aligned}
& =\mathrm{SST}_{\mathrm{r}}-\{\mathrm{SSP}-\mathrm{SSS}-\mathrm{SSQ}-\mathrm{SSPS}-\mathrm{SSSQ}-\mathrm{SSPQ}\} \\
& =2504-1952-130.66-44.66-177.34-46.68-33.34=119.32
\end{aligned}
$$


Table 15. $3^{3}$ Design Matrix for Induction Hardening with Test results Material: AISI 1055 (Surface Hardness)

\begin{tabular}{|c|c|c|c|c|c|c|}
\hline \multirow{2}{*}{ S. No. } & \multirow{2}{*}{$\mathbf{P}$} & \multirow{2}{*}{$\mathbf{S}$} & \multirow{2}{*}{$\mathbf{Q}$} & \multicolumn{3}{|c|}{ Hardness in HRA } \\
\hline & & & & Trial 1 & Trial 2 & Trial 3 \\
\hline 1 & 5.5 & 1.34 & 15 & 83 & 84 & 85 \\
\hline 2 & 5.5 & 1.34 & 17.5 & 82 & 83 & 84 \\
\hline 3 & 5.5 & 1.34 & 20 & 83 & 84 & 85 \\
\hline 4 & 5.5 & 1.72 & 15 & 78 & 81 & 81 \\
\hline 5 & 5.5 & 1.72 & 17.5 & 79 & 80 & 81 \\
\hline 6 & 5.5 & 1.72 & 20 & 83 & 84 & 85 \\
\hline 7 & 5.5 & 2.14 & 15 & 80 & 81 & 82 \\
\hline 8 & 5.5 & 2.14 & 17.5 & 82 & 83 & 84 \\
\hline 9 & 5.5 & 2.14 & 20 & 81 & 82 & 83 \\
\hline 10 & 7.05 & 1.34 & 15 & 77 & 78 & 79 \\
\hline 11 & 7.05 & 1.34 & 17.5 & 77 & 81 & 82 \\
\hline 12 & 7.05 & 1.34 & 20 & 77 & 79 & 78 \\
\hline 13 & 7.05 & 1.72 & 15 & 69 & 71 & 70 \\
\hline 14 & 7.05 & 1.72 & 17.5 & 78 & 76 & 77 \\
\hline 15 & 7.05 & 1.72 & 20 & 79 & 81 & 80 \\
\hline 16 & 7.05 & 2.14 & 15 & 75 & 76 & 74 \\
\hline 17 & 7.05 & 2.14 & 17.5 & 74 & 72 & 73 \\
\hline 18 & 7.05 & 2.14 & 20 & 73 & 74 & 72 \\
\hline 19 & 8.5 & 1.34 & 15 & 78 & 77 & 79 \\
\hline 20 & 8.5 & 1.34 & 17.5 & 71 & 69 & 70 \\
\hline 21 & 8.5 & 1.34 & 20 & 69 & 67 & 68 \\
\hline 22 & 8.5 & 1.72 & 15 & 69 & 71 & 70 \\
\hline 23 & 8.5 & 1.72 & 17.5 & 75 & 74 & 73 \\
\hline 24 & 8.5 & 1.72 & 20 & 71 & 70 & 69 \\
\hline 25 & 8.5 & 2.14 & 15 & 68 & 66 & 67 \\
\hline 26 & 8.5 & 2.14 & 17.5 & 70 & 69 & 68 \\
\hline 27 & 8.5 & 2.14 & 20 & 72 & 71 & 73 \\
\hline
\end{tabular}

Table 16. ANOVA with F-Test Material: AISI 4340 (Surface Hardness)

\begin{tabular}{|c|c|c|c|c|c|}
\hline Variable & Sum of Squares & Degrees of Freedom & Mean Square & $\mathbf{F}$ & Significant Ranking \\
\hline Replicates & 2 & 2 & 1 & 0.6345 & - \\
\hline $\mathrm{S}$ & 130.66 & 2 & 65.33 & 41.453 & 2 \\
\hline Q & 44.66 & 2 & 22.33 & 14.168 & 4 \\
\hline PQ & 33.34 & 4 & 8.335 & 5.288 & 7 \\
\hline PSQ & 119.32 & 8 & 14.915 & 9.463 & 5 \\
\hline ERROR & 82 & 52 & 1.576 & - & \\
\hline TOTAL & - & 80 & & & \\
\hline
\end{tabular}


Regression analysis is done using MATLAB and the Regression equations (Equation to predict the hardness of the material AISI 4340) are found and given below.

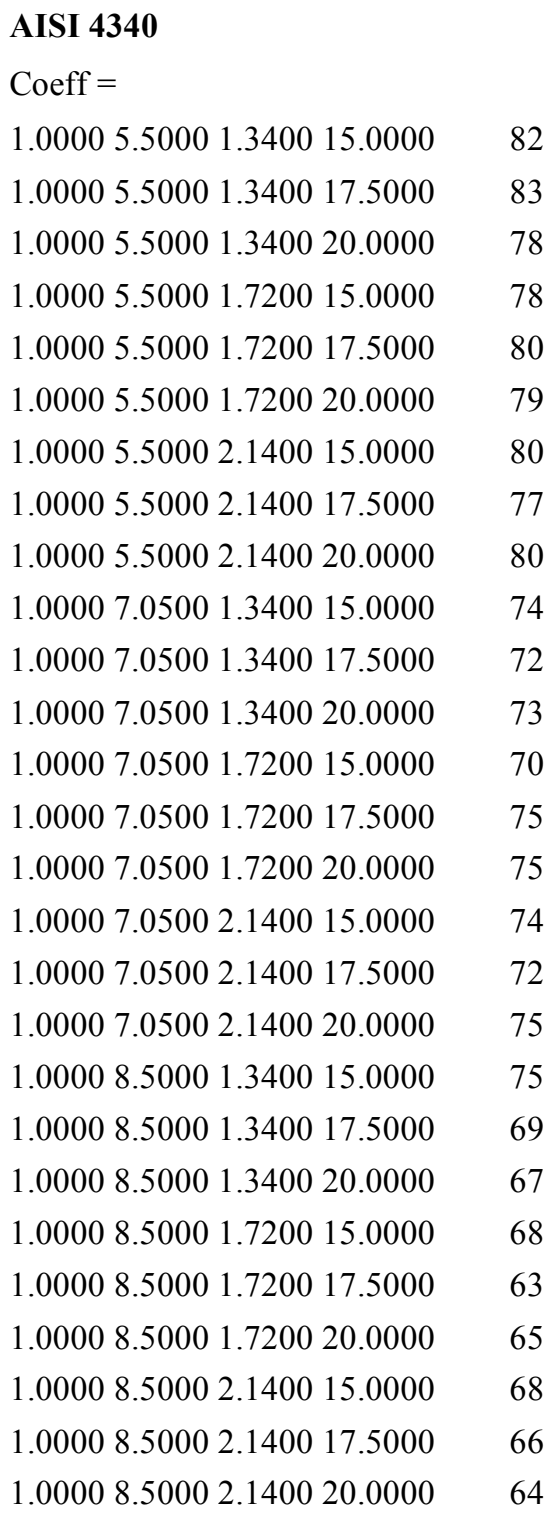

The coefficients for the formation of hardness equation are,

\subsection{1 \\ $-4.1474$ \\ $-2.3059$ \\ $\mathbf{- 0 . 2 8 8 9}$}

Equation to Predict the Hardness of the Material AISI 4340

$Y_{H}=111.5611-4.1474 P-2.3059 S-0.2889 Q$

Similarly, for the material AISI 1055, equation to predict the hardness is given by

$Y_{H}=106.7885-3.8179 P-3.38671 S-0.1778 Q$

\subsection{Case Depth Optimization in Rack}

After Induction hardening a steel component is usually hardness/ Case depth tested. And the value obtained is a good indication of the effectiveness of the treatment [17]. The case depth can be measured either by Visual examination or by Hardness measurement. The case depth/Hardness test is carried out by pressing a ball or point with a predetermined force into the surface of the specimen. The hardness figure is function of the size of the indentation for the Brinell (HB) and Vickers (HV), tests and of the depth of the penetration for Rockwell (HRC) test. The above three methods are the most commonly used tests and each has its special range of application and between them they cover almost the whole for the hardness/Case depth field that is of interest of the steel producer and user [18-19].

The present study explains the optimization [20] of critical process variables involved in the Induction hardening of a Rack material (Fig. 10) used in the power steering of the automobile to get higher case depth [21].

In order to study the influence of process variables on the Case depth of the Rack material below the teeth and back of the bar for the AISI 4340 and AISI 1055 Rack materials Induction hardening experiments are conducted.

Table 12 shows the details about the operating conditions.

Table 17. ANOVA with F-Test Material: AISI 1055 (Surface Hardness)

\begin{tabular}{|c|c|c|c|c|c|}
\hline Variable & Sum of Squares & Degrees of Freedom & Mean Square & $\mathbf{F}$ & Significant Ranking \\
\hline Replicates & 6.745 & 2 & 3.3725 & 2.771 & - \\
\hline S & 134.22 & 2 & 67.11 & 55.143 & 2 \\
\hline Q & 11.56 & 2 & 5.78 & 4.749 & 7 \\
\hline SQ & 157.78 & 4 & 39.445 & 32.411 & 3 \\
\hline PQ & 53.11 & 4 & 13.2775 & 10.910 & 5 \\
\hline PSQ & 229.55 & 8 & 28.69 & 23.574 & 4 \\
\hline ERROR & 63.295 & 52 & 1.217 & - & \\
\hline
\end{tabular}


(a)

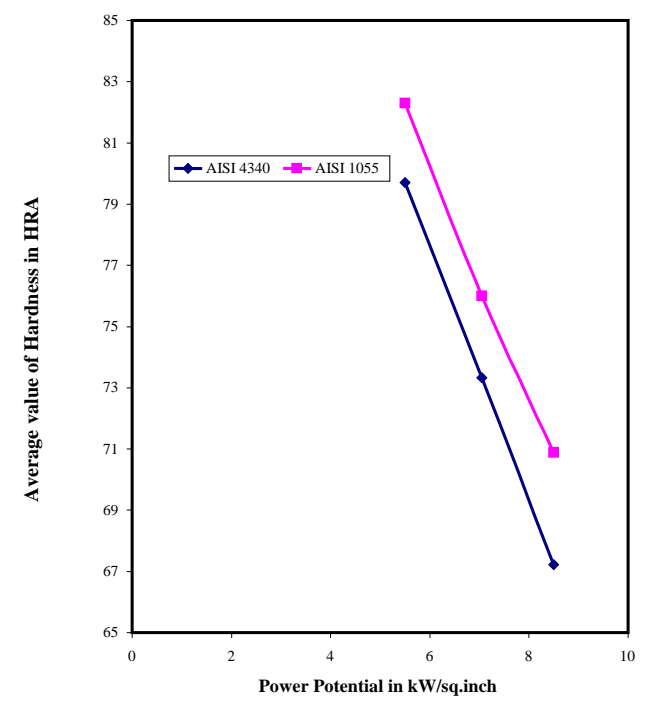

(b)

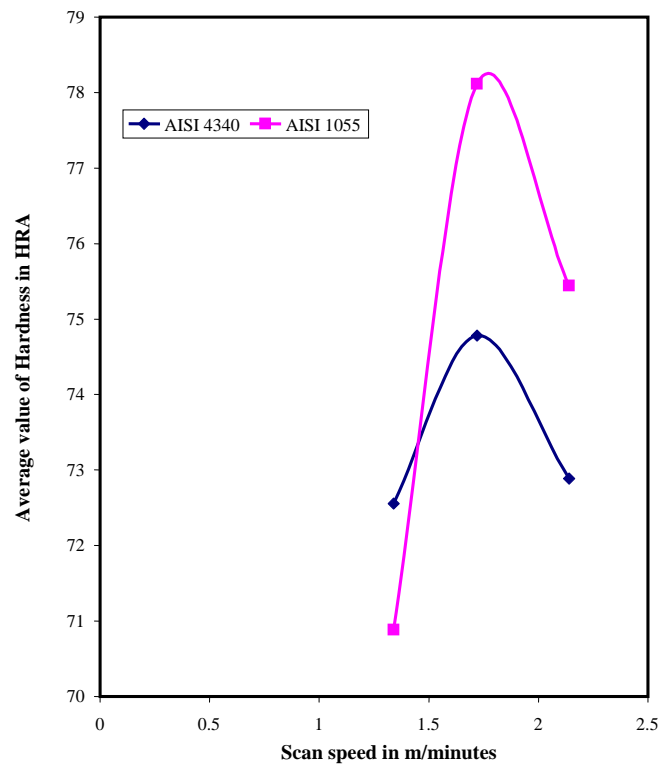

(c)

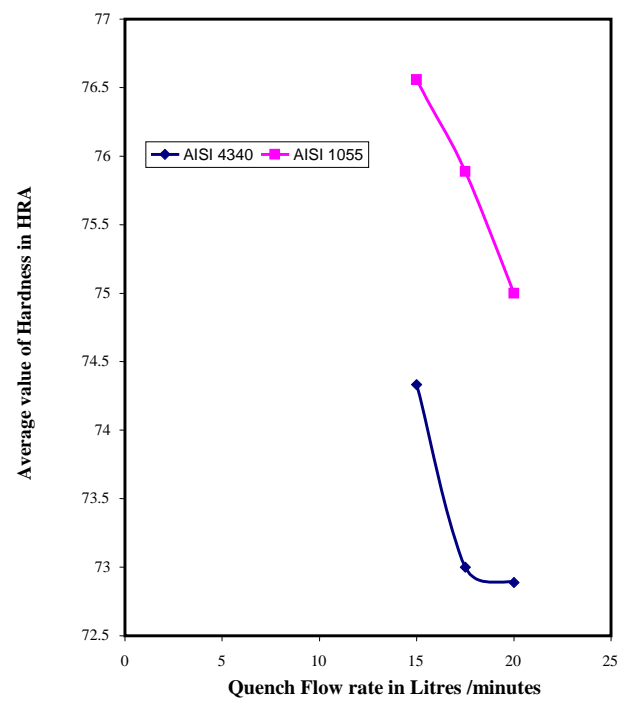

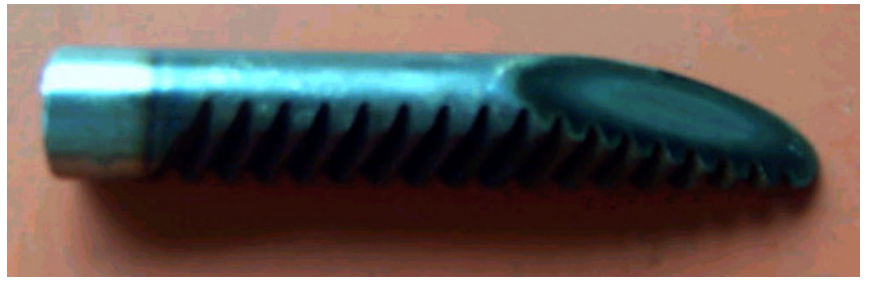

Fig. (10). Cut section of an induction hardened rack component.

Tables 18 and 19 shows the Experimental results in the $3^{3}$ Design Matrix for the materials AISI 4340 and AISI 1055 respectively.

Tables 20 and $\mathbf{2 1}$ shows the ANOVA with F-Test of the material AISI 4340 for case depth Below the teeth and Back of the bar respectively.

Tables 22 and $\mathbf{2 3}$ shows the ANOVA with F-Test of the material AISI 1055 for case depth Below the teeth and Back of the bar respectively.

5.2.1. Influence of Main Variables on Case Depth of Rack Material (Below the Teeth and Back of the Bar for AISI 4340)

5.2.1.1. Model Calculation (Case Depth - Below the Teeth)

Total sum of the run

$$
=(2.4+2.6+2.5+\ldots .1 .6+1.4+1.5)=142
$$

Number of Treatments

$$
=3 \text { (3 Factors) }
$$

Number of Levels $=3$

Number of replicates

(r)

$$
=3
$$

Total of the observations

under all factor levels

$$
=\mathrm{N}=\mathrm{abcr}=3 \times 3 \times 3 \times 3=81
$$

Correction factor, (C)

$$
\begin{aligned}
& =(142)^{2} / 81 \\
& =248.93
\end{aligned}
$$

Sum of Squares of Treatment, (SST)

$$
\begin{aligned}
& =\left(2.4^{2}+2.6^{2}+2.5^{2}+\ldots 1.6^{2}+1.4^{2}+1.5^{2}\right) \\
& =(261.56)-\mathrm{C} \\
& =12.63
\end{aligned}
$$

Sum of Squares of Treatment with replicates, $\left(\mathrm{SST}_{\mathrm{r}}\right)$

$$
\begin{aligned}
& =1 / 3\left(7.5^{2}+6.9^{2}+\ldots 4.5^{2}\right) \\
& =1 / 3(783.4)-\mathrm{C} \\
& =12.20
\end{aligned}
$$

Sum of Squares of Replicate, (SSR)

$$
\begin{aligned}
& =1 / 27\left(47.3^{2}+47.1^{2}+47.6^{2}\right)-\mathrm{C} \\
& =0.013
\end{aligned}
$$

Sum of Squares of Error, (SSE)

$$
\begin{aligned}
& =\mathrm{SST}_{-\mathrm{SST}_{\mathrm{r}}-\mathrm{SSR}} \\
& =12.63-12.20-0.013 \\
& =0.417
\end{aligned}
$$

Fig. (9). (a-c) Process variables vs surface hardness. 


\begin{tabular}{|c|c|c|c|c|c|c|c|c|c|c|c|}
\hline 57.6 & 20.1 & 20.1 & 17.4 & \multirow{2}{*}{$\mathrm{P}$} & & & & 49.3 & 17.1 & 16.6 & 15.6 \\
\hline 38.2 & 13.0 & 12.3 & 12.9 & & & & & 45.9 & 17.4 & 14.7 & 13.8 \\
\hline 142 & 49.3 & 46.8 & 45.9 & 57.6 & 21 & 18.6 & 18 & 142 & 48.9 & 48.1 & 45 \\
\hline \multirow{2}{*}{$\mathrm{P}$} & & & & 38.2 & 12.3 & 13.6 & 12.3 & \multirow{2}{*}{$\mathrm{S}$} & & & \\
\hline & & & & 142 & 48.9 & 48.1 & 45.0 & & & & \\
\hline
\end{tabular}

Table 18. $3^{3}$ Design Matrix for Induction Hardening with Test Results Material: AISI 4340 (Case Depth)

\begin{tabular}{|c|c|c|c|c|c|c|c|c|c|}
\hline \multirow[t]{2}{*}{ S. No. } & \multirow[t]{2}{*}{$\mathbf{P}$} & \multirow[t]{2}{*}{$\mathbf{S}$} & \multirow[t]{2}{*}{$\mathbf{Q}$} & \multicolumn{3}{|c|}{$\begin{array}{c}\text { Case Depth } \\
\text { Below the Teeth }\end{array}$} & \multicolumn{3}{|c|}{$\begin{array}{c}\text { Case Depth } \\
\text { Back of the Bar }\end{array}$} \\
\hline & & & & Trial 1 & Trial 2 & Trial 3 & Trial 1 & Trial 2 & Trial 3 \\
\hline 1 & 5.5 & 1.34 & 15 & 2.4 & 2.6 & 2.5 & 4.3 & 4.3 & 4.3 \\
\hline 2 & 5.5 & 1.34 & 17.5 & 2.2 & 2.4 & 2.3 & 4.1 & 4.0 & 4.2 \\
\hline 5 & 5.5 & 1.72 & 17.5 & 2 & 2 & 2 & 1.2 & 1.0 & 1.1 \\
\hline 6 & 5.5 & 1.72 & 20 & 2.4 & 2.2 & 2.3 & 2.4 & 2.2 & 2.3 \\
\hline 7 & 5.5 & 2.14 & 15 & 2.5 & 2.5 & 2.5 & 4.0 & 4.0 & 4.0 \\
\hline 11 & 7.05 & 1.34 & 17.5 & 1.5 & 1.5 & 1.5 & 2.6 & 2.7 & 2.8 \\
\hline 12 & 7.05 & 1.34 & 20 & 2 & 2 & 2 & 1.8 & 2.2 & 2.0 \\
\hline 13 & 7.05 & 1.72 & 15 & 1.5 & 1.5 & 1.5 & 3 & 3.1 & 3.2 \\
\hline 14 & 7.05 & 1.72 & 17.5 & 1.6 & 1.7 & 1.8 & 2.3 & 2.2 & 2.4 \\
\hline 15 & 7.05 & 1.72 & 20 & 1.5 & 1.8 & 1.5 & 3.4 & 3.5 & 3.6 \\
\hline 16 & 7.05 & 2.14 & 15 & 1.9 & 1.7 & 1.8 & 2.7 & 2.5 & 2.9 \\
\hline 17 & 7.05 & 2.14 & 17.5 & 2.1 & 2 & 2.2 & 2.9 & 2.9 & 2.9 \\
\hline 18 & 7.05 & 2.14 & 20 & 1.3 & 1.3 & 1.3 & 1.7 & 1.7 & 2.0 \\
\hline 25 & 8.5 & 2.14 & 15 & 1.5 & 1.5 & 1.5 & 1.2 & 1.2 & 1.2 \\
\hline 26 & 8.5 & 2.14 & 17.5 & 1.4 & 1.3 & 1.2 & 1.2 & 1.3 & 1.4 \\
\hline 27 & 8.5 & 2.14 & 20 & 1.6 & 1.4 & 1.5 & 1.0 & 1.1 & 1.2 \\
\hline
\end{tabular}


Table 19. $3^{3}$ Design Matrix for Induction Hardening with Test Results Material: AISI 1055 (Case Depth)

\begin{tabular}{|c|c|c|c|c|c|c|c|c|c|}
\hline \multirow[t]{2}{*}{ S. No. } & \multirow[t]{2}{*}{$\mathbf{P}$} & \multirow[t]{2}{*}{$\mathbf{S}$} & \multirow[t]{2}{*}{$\mathbf{Q}$} & \multicolumn{3}{|c|}{$\begin{array}{c}\text { Case Depth } \\
\text { Below the Teeth }\end{array}$} & \multicolumn{3}{|c|}{$\begin{array}{c}\text { Case Depth } \\
\text { Back of the Bar }\end{array}$} \\
\hline & & & & Trial 1 & Trial 2 & Trial 3 & Trial 1 & Trial 2 & Trial 3 \\
\hline 1 & 5.5 & 1.34 & 15 & 2.2 & 2.4 & 2.3 & 4 & 4.1 & 4.2 \\
\hline 2 & 5.5 & 1.34 & 17.5 & 2.0 & 2.2 & 2.1 & 3.9 & 4 & 3.8 \\
\hline 3 & 5.5 & 1.34 & 20 & 2.2 & 2.0 & 2.1 & 4.1 & 4.2 & 4 \\
\hline 4 & 5.5 & 1.72 & 15 & 1.9 & 1.9 & 1.9 & 3.7 & 3.6 & 3.8 \\
\hline 5 & 5.5 & 1.72 & 17.5 & 1.9 & 2.0 & 1.8 & 3.2 & 3 & 3.1 \\
\hline 6 & 5.5 & 1.72 & 20 & 2.1 & 2.0 & 2.2 & 3.5 & 3.4 & 3.3 \\
\hline 7 & 5.5 & 2.14 & 15 & 2.3 & 2.1 & 2.2 & 3 & 3 & 3 \\
\hline 8 & 5.5 & 2.14 & 17.5 & 1.1 & 1.1 & 1.1 & 2.9 & 2.7 & 2.8 \\
\hline 9 & 5.5 & 2.14 & 20 & 1.8 & 1.6 & 1.7 & 4 & 4 & 4 \\
\hline 10 & 7.05 & 1.34 & 15 & 1.8 & 1.8 & 1.8 & 3.7 & 3.9 & 3.8 \\
\hline 11 & 7.05 & 1.34 & 17.5 & 1.8 & 1.8 & 1.8 & 3.3 & 3.1 & 3.2 \\
\hline 12 & 7.05 & 1.34 & 20 & 1.7 & 1.6 & 1.8 & 3.4 & 3.3 & 3.5 \\
\hline 13 & 7.05 & 1.72 & 15 & 1.6 & 1.6 & 1.6 & 3.5 & 3.5 & 3.5 \\
\hline 14 & 7.05 & 1.72 & 17.5 & 2.0 & 1.9 & 1.8 & 3.7 & 3.6 & 3.5 \\
\hline 15 & 7.05 & 1.72 & 20 & 1.7 & 2.0 & 1.7 & 2 & 2.2 & 2.1 \\
\hline 16 & 7.05 & 2.14 & 15 & 1.7 & 1.7 & 2.0 & 2.8 & 2.7 & 2.9 \\
\hline 17 & 7.05 & 2.14 & 17.5 & 1.3 & 1.1 & 1.2 & 3.2 & 2.8 & 3 \\
\hline 18 & 7.05 & 2.14 & 20 & 1.8 & 1.9 & 1.7 & 2.1 & 2 & 2.2 \\
\hline 19 & 8.5 & 1.34 & 15 & 1.2 & 1.4 & 1.3 & 2 & 1.7 & 1.7 \\
\hline 20 & 8.5 & 1.34 & 17.5 & 1.4 & 1.4 & 1.4 & 1.3 & 1.2 & 1.1 \\
\hline 21 & 8.5 & 1.34 & 20 & 1.3 & 1.2 & 1.4 & 1.7 & 1.5 & 1.6 \\
\hline 22 & 8.5 & 1.72 & 15 & 1.4 & 1.6 & 1.8 & 1.9 & 1.8 & 1.7 \\
\hline 23 & 8.5 & 1.72 & 17.5 & 1.5 & 1.7 & 1.9 & 0.8 & 1 & 0.9 \\
\hline 24 & 8.5 & 1.72 & 20 & 1.4 & 1.3 & 1.5 & 1.3 & 1.2 & 1.1 \\
\hline 25 & 8.5 & 2.14 & 15 & 1.3 & 1.4 & 1.2 & 1.6 & 1.6 & 1.6 \\
\hline 26 & 8.5 & 2.14 & 17.5 & 1.4 & 1.6 & 1.5 & 0.8 & 1 & 0.9 \\
\hline 27 & 8.5 & 2.14 & 20 & 1.3 & 1.5 & 1.4 & 1.3 & 1.5 & 1.4 \\
\hline
\end{tabular}

\subsubsection{Sum of Squares of Main Effect ( $P, S$ and $Q)$}

Sum of Square of Power Potential, SSP

$$
=\left[1 / 27\left(57.6^{2}+46.2^{2}+38.2^{2}\right)\right]-\mathrm{C} \quad=7.05
$$

Sum of Square of Scan Speed, SSS

$$
=\left[1 / 27\left(49.3^{2}+46.8^{2}+45.9^{2}\right)\right]-\mathrm{C} \quad=0.23
$$

Sum of Square of Quench flow rate, SSQ

$$
=\left[1 / 27\left(48.9^{2}+48.1^{2}+45^{2}\right)\right]-\mathrm{C} \quad=0.32
$$

5.2.3. Two Way Interactions of Sum of Squares (PS, $S Q$ and $P Q$ )

Sum of Square of Power Potential and Scan Speed

$$
=\left[1 / 9\left(20.1^{2}+\ldots 12.9^{2}\right)\right]-\mathrm{C}=0.52
$$

Sum of Square of Scan Speed and Quench flow rate

$$
=\left[1 / 9\left(17.1^{2}+\ldots .13 .8^{2}\right)\right]-\mathrm{C}=0.91
$$

Sum of Square of Power Potential and Quench flow rate

$=\left[1 / 9\left(21^{2}+\ldots 12.3^{2}\right)\right]-\mathrm{C}=0.45$

\subsubsection{Three Way Interactions of Sum of Square (PSQ)}

Sum of Square of Power Potential, Scan speed and

Quench flow rate

$$
\begin{aligned}
& =\mathrm{SST}_{\mathrm{r}}-\{\mathrm{SSP}-\mathrm{SSS}-\mathrm{SSQ}-\mathrm{SSPS}-\mathrm{SSSQ}-\mathrm{SSPQ}\} \\
& =12.20-7.05-0.238-0.32-0.52-0.91-0.45 \\
& =2.712
\end{aligned}
$$

5.2.4.1. Model Calculation (Case Depth- Back of the Bar) Total sum of the run

$$
=(4.3+4.3+4.3+\ldots .1 .0+1.1+1.2)=191.8
$$


Number of Treatments

$$
=3 \text { (3 Factors) }
$$

Number of Levels

$$
=3
$$

Number of replicates (r)

$$
=3
$$

Total of the observations

under all factor levels

$$
=\mathrm{N}=\mathrm{abcr}=3 \times 3 \times 3 \times 3=81
$$

Correction factor, $(\mathrm{C})$

$$
\begin{aligned}
& =(191.8)^{2} / 81 \\
& =454.16
\end{aligned}
$$

Sum of Squares of Treatment, (SST)

$$
\begin{aligned}
& =\left(4.3^{2}+4.3^{2}+4.3^{2}+\ldots 1.0^{2}+1.1^{2}+1.2^{2}\right) \\
& =(535.93)-\mathrm{C} \\
& =81.8
\end{aligned}
$$

Sum of Squares of Treatment with replicates, $\left(\mathrm{SST}_{\mathrm{r}}\right)$

$$
\begin{aligned}
& =1 / 3\left(12.9^{2}+12.3^{2}+\ldots 3.3^{2}\right) \\
& =1 / 3(1604.44)-\mathrm{C} \\
& =80.65
\end{aligned}
$$

Sum of Squares of Replicate, (SSR)

$$
\begin{aligned}
& =1 / 27\left(63^{2}+63.5^{2}+65.3^{2}\right)-\mathrm{C} \\
& =0.111
\end{aligned}
$$

Sum of Squares of Error, (SSE)

$$
\begin{aligned}
& =\mathrm{SST}_{-\mathrm{SST}_{\mathrm{r}}-\mathrm{SSR}} \\
& =81.8-80.65-0.111 \\
& =1.039
\end{aligned}
$$

\begin{tabular}{|c|c|c|c|c|c|c|c|c|c|c|c|}
\hline & \multicolumn{3}{|c|}{$\mathbf{S}$} & & \multicolumn{3}{|c|}{$\mathbf{Q}$} & & \multicolumn{3}{|c|}{$\mathbf{Q}$} \\
\hline 84.6 & 35.1 & 18.6 & 30.9 & \multirow{2}{*}{$\mathrm{P}$} & & & & 72.1 & 27.4 & 25.2 & 19.5 \\
\hline 36.1 & 14.8 & 10.5 & 10.8 & & & & & 63.9 & 23.7 & 21.3 & 18.9 \\
\hline 191.8 & 72.1 & 55.8 & 63.9 & 84.6 & 28.2 & 29.4 & 27.0 & 191.8 & 67.9 & 64.5 & 59.4 \\
\hline \multirow{2}{*}{$\mathrm{P}$} & & & & 36.1 & 14.2 & 11.4 & 10.5 & \multirow{2}{*}{$\mathrm{S}$} & & & \\
\hline & & & & 191.8 & 67.9 & 64.5 & 59.4 & & & & \\
\hline
\end{tabular}

\subsubsection{Sum of Squares of Main effect (P, S and $Q)$}

Sum of Square of Power Potential, SSP

$$
=\left[1 / 27\left(84.6^{2}+71.1^{2}+36.1^{2}\right)\right]-\mathrm{C}=46.417
$$

Sum of Square of Scan Speed, SSS

$$
=\left[1 / 27\left(72.1^{2}+55.8^{2}+63.9^{2}\right)\right]-\mathrm{C}=4.923
$$

Sum of Square of Quench flow rate, SSQ

$$
=\left[1 / 27\left(67.9^{2}+64.5^{2}+59.4\right)\right]-\mathrm{C}=1.359
$$

5.3.2. Two Way Interactions of Sum of Squares (PS, SQ and $P Q$ )

Sum of Square of Power Potential and Scan Speed

$$
=\left[1 / 9\left(35.1^{2}+\ldots 10.8^{2}\right)\right]-\mathrm{C}=14.19
$$

Sum of Square of Scan Speed and Quench flow rate $=\left[1 / 9\left(27.4^{2}+\ldots .18 .9^{2}\right)\right]-\mathrm{C}=4.65$

Table 20. ANOVA with F-Test Material: AISI 4340 (Case Depth Below the Teeth)

\begin{tabular}{|c|c|c|c|c|c|}
\hline Variable & Sum of Squares & Degrees of Freedom & Mean Square & F & 0.810 \\
\hline \hline Replicates & 0.013 & 2 & 0.0065 & 439.526 & 14.837 \\
\hline P & 7.05 & 2 & 3.525 & 19.950 & 6 \\
\hline S & 0.238 & 2 & 0.119 & 16.209 & 4 \\
\hline Q & 0.320 & 2 & 0.160 & 28.366 & 5 \\
\hline PS & 0.520 & 4 & 0.130 & 14.027 & 3 \\
\hline SQ & 0.910 & 4 & 0.2275 & 42.269 & 7 \\
\hline PQ & 0.450 & 4 & 0.1125 & & 2 \\
\hline PSQ & 2.712 & 52 & 0.00802 & & \\
\hline ERROR & 0.417 & 80 & & & \\
\hline TOTAL & - & & & \\
\hline
\end{tabular}


Sum of Square of Power Potential and

Quench flow rate $=\left[1 / 9\left(28.2^{2}+\ldots 10.5^{2}\right)\right]-\mathrm{C}=0.508$

\subsubsection{Three Way Interactions of Sum of Square (PSQ)}

Sum of Square of Power Potential, Scan speed and Quench flow rate

$$
\begin{aligned}
& =\mathrm{SST}_{\mathrm{r}}-\{\mathrm{SSP}-\mathrm{SSS}-\mathrm{SSQ}-\mathrm{SSPS}-\mathrm{SSSQ}-\mathrm{SSPQ}\} \\
& =80.65-46.417-4.923-1.359-14.19-4.65-0.508 \\
& =8.603
\end{aligned}
$$

Regression analysis is done using MATLAB and the Regression equations (Equation to predict the Case depth (Below the teeth and Back of the bar) of the material AISI 4340) are found and given below.

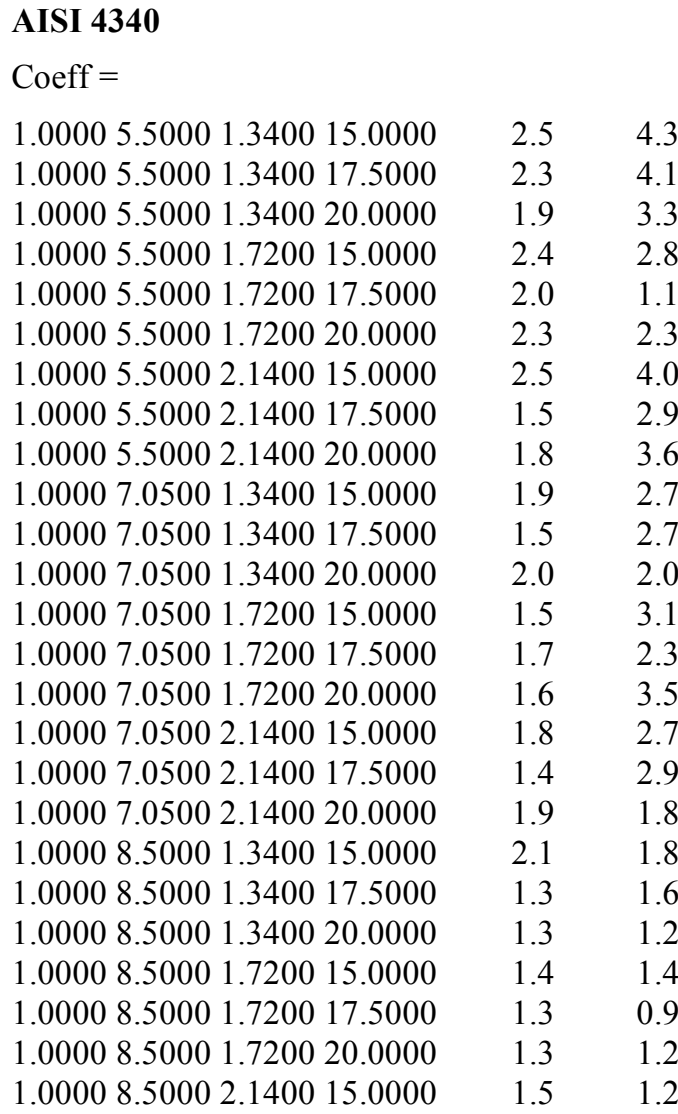

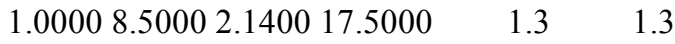

$1.00008 .50002 .140020 .0000 \quad 1.5 \quad 1.2$

The coefficients for the formation of case depth (below the teeth and back of the bar) equation are,

\subsection{8 .0291 \\ $-0.2265-0.6135$ \\ $-0.2127-0.2797$ \\ $-0.0367-0.0500$}

Equations to predict the Case depth (below the teeth and back of the bar) of the material AISI 4340 are given under.

$Y_{B T}=4.3660-0.2265 P-0.2127 S-0.0367 Q$

$Y_{B B}=8.0291-0.6135 P-0.2797 S-0.0500 Q$

Similarly equation to predict the Case depth (below the teeth and back of the bar) of the material AISI 1055

$Y_{B T}=3.4984-0.1683 P-0.2474 S-0.0111 Q$

$Y_{B B}=10.0772-0.7195 P-0.7582 S-0.0600 Q$

\section{RESULTS AND DISCUSSION}

\subsection{Optimization of Carburizing Process Variables}

The present research is concerned with the optimization of process variables and identification of the root cause for the inconsistency in hardness and case depth and distortion in Gas carburized materials, e.g., pinion. After holding extensive consultation with the personnels of all the departments in the industry in which this research has been carried out, it is concluded that preheating, carbon potential, holding position, furnace temperature, carburising time, quenching medium, quenching temperature, quenching time, tempering temperature and tempering time are the influential variables responsible for the surface integrity of the components. Based on this a Cause and Effect Analysis is made and Shewerts' diagram (Fig. 12) is drawn.

The optimization result (Table 7) and Response graphs (Figs. 4e, 6e) indicates that preheating the material before subjecting to Gas carburizing process improves the hardness and case depth. Even though, this process is employed to relieve the internal stresses, no remarkable microstructural

\begin{tabular}{|c|c|c|c|c|c|}
\hline Variable & Sum of Squares & Degrees of Freedom & Mean Square & $\mathbf{F}$ & Significant Ranking \\
\hline Replicates & 0.111 & 2 & 0.0555 & 2.788 & \\
\hline $\mathrm{P}$ & 46.417 & 2 & 23.2085 & 1166.256 & 1 \\
\hline $\mathrm{S}$ & 4.923 & 2 & 2.4615 & 123.693 & 3 \\
\hline $\mathrm{Q}$ & 1.359 & 2 & 0.6795 & 34.145 & 6 \\
\hline PS & 14.190 & 4 & 3.5475 & 178.266 & 2 \\
\hline SQ & 4.650 & 4 & 1.1625 & 58.417 & 4 \\
\hline PQ & 0.508 & 4 & 0.127 & 6.3819 & 7 \\
\hline PSQ & 8.603 & 8 & 1.075 & 54.020 & 5 \\
\hline ERROR & 1.039 & 52 & 0.0199 & - & \\
\hline TOTAL & - & 80 & & & \\
\hline
\end{tabular}
changes occur during this process. Internal stresses are

Table 21. ANOVA with F-Test Material: AISI 4340 (Case Depth Back of the Bar) 
Table 22. ANOVA with F-Test - Material: AISI 1055 (Case Depth Below the Teeth)

\begin{tabular}{|c|c|c|c|c|c|}
\hline Variable & Sum of Squares & Degrees of Freedom & Mean Square & F & 1.201 \\
\hline \hline Replicates & 0.0274 & 2 & 0.0137 & 140.350 & 1 \\
\hline P & 3.340 & 2 & 1.60 & 33.772 & 2 \\
\hline S & 0.770 & 2 & 0.385 & 10.833 & 6 \\
\hline Q & 0.247 & 2 & 0.1235 & 18.640 & 5 \\
\hline PS & 0.850 & 4 & 0.2125 & 23.684 & 3 \\
\hline SQ & 1.080 & 4 & 0.270 & 9.517 & 7 \\
\hline PQ & 0.890 & 4 & 0.2225 & 9.423 & - \\
\hline PSQ & 0.860 & 8 & 0.0114 & & 7 \\
\hline ERROR & 0.5926 & 52 & & & \\
\hline TOTAL & - & 80 & & \\
\hline
\end{tabular}

Table 23. ANOVA with F-Test - Material: AISI 1055 (Case Depth Back of the Bar)

\begin{tabular}{|c|c|c|c|c|c|}
\hline Variable & Sum of Squares & Degrees of Freedom & Mean Square & $\mathbf{F}$ & Significant Ranking \\
\hline Replicates & 0.0274 & 2 & 0.0137 & 1.507 & - \\
\hline $\mathrm{S}$ & 5.286 & 2 & 2.643 & 290.823 & 2 \\
\hline $\mathrm{Q}$ & 2.286 & 2 & 1.143 & 125.770 & 4 \\
\hline SQ & 1.768 & 4 & 0.442 & 48.635 & 5 \\
\hline PQ & 5.334 & 4 & 1.3335 & 146.73 & 3 \\
\hline PSQ & 2.432 & 8 & 0.304 & 33.450 & 6 \\
\hline ERROR & 0.4726 & 52 & 0.009088 & - & \\
\hline
\end{tabular}

developed during machining and grinding. This precarburizing process removes these stresses. It holds well with the remarks given by Shen-Chih Lee and Wei-Youe Ho (1989) in their paper "The effects of surface hardening on Fracture Toughness of Carburized steel" [22]. Further, it is observed that the extent to which the stresses can be relieved depends on the temperature employed, holding time and uniformity in cooling.

Tables $\mathbf{6}$ and $\mathbf{1 1}$ shows that furnace temperature is having a significant effect on obtainable hardness and case depth. The reason for this may be given as below. At higher furnace temperature, formation of water vapour is less. Water vapour is a strongly decarburizing gas but whether this decarburizing tendency will actually reveal itself in practice depends on a number of factors. The first is the concentration in which the water vapour is present and the second is the nature of the carburizing gases in particular gas mixture under consideration. There is perhaps, more contradictory evidence on this subject of the effect of water vapour in gas carburizing and in the heat treatment of steels than any other single item and it is quite clear that a lot more work remains to be carried out before an absolutely clear picture is obtained. It is possible that in small amount, water vapour actually has a beneficial effect on carburizing, an effect which seems to be catalytic in nature. However, the present study shows that higher furnace temperature $\left(940^{\circ} \mathrm{C}\right)$ gives high hardness and case depth.

In the present analysis, Optimum Gas Carburising Process conditions to obtain higher surface hardness with more case depth are given in Table 24.

Analysis of variance is done for EN 29 and EN 34. The ANOVA results (Tables 6 and 11) and optimum conditions for hardness and Case depth (Table 7 - Response graph and $\mathrm{S} / \mathrm{N}$ ratio) indicate that the interaction between Furnace temperature and quenching time is having $25-30 \%$ influence on the hardness and case depth. Further, the present optimization analysis shows that Signal to noise ratio method has also given the same optimal variable levels/best treatment combination levels with the Response Graph analysis.

To check the optimum results obtained through Taguchis' DOE, confirmation trials are carried out and the results are tabulated in Table $\mathbf{2 5}$. From the table it is clear that the predicted conditions for higher hardness and case depth suits well with the experimental results. 
(a)

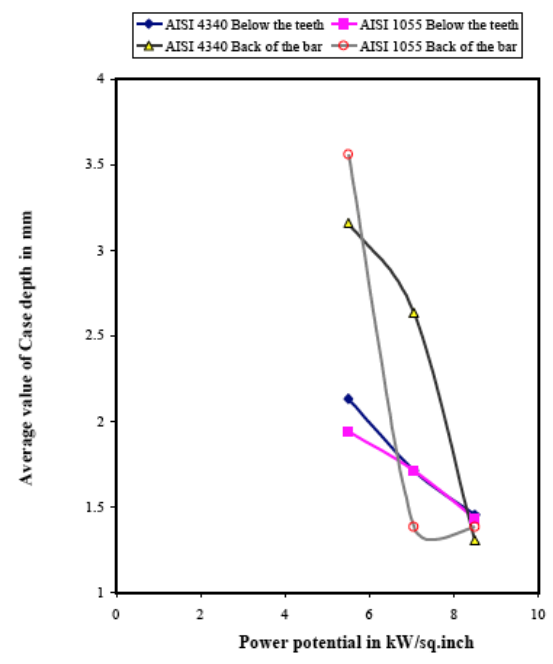

(b)

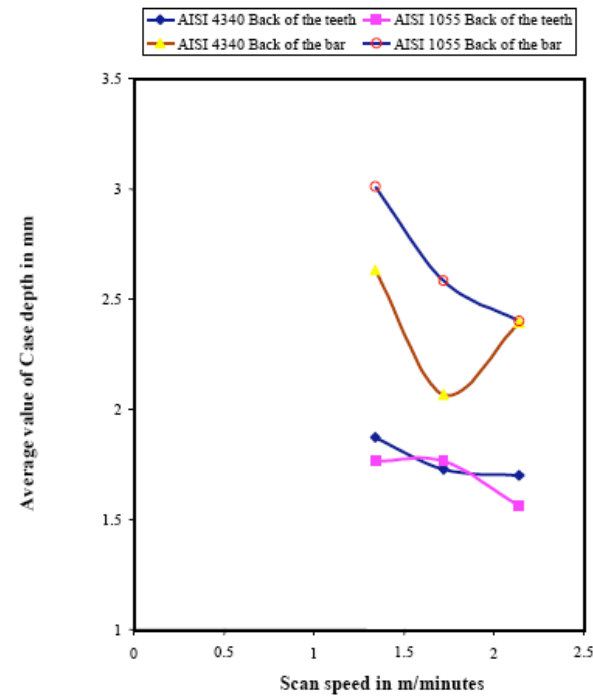

(c)

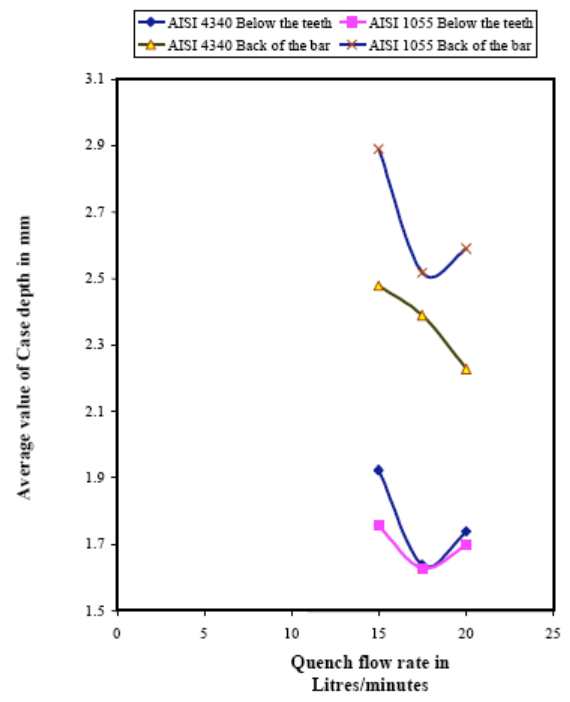

Fig. (11). (a-c) Process variables vs Case depth.

EN 34 (Nickel Molybdenum alloy steel) are characterized by higher tensile strength and toughness values, improved fatigue strength, impact resistance and shear strength. EN 29 (Chromium Molybdenum alloy steel) steels are generally case carburized. Increasing Chromium content increases the wear resistance of case. However, toughness in the core is somewhat reduced by increasing Chromium content. The experimental values (EN 29: Maximum case depth $-1 \mathrm{~mm}$ and Maximum hardness -81.5 HRA, EN 34: Maximum case depth $-0.9625 \mathrm{~mm}$ and Maximum Hardness - 80.5 HRA) on case depth and Hardness shows that Chromium Molybdenum steel is giving a slightly higher hardness and case depth than the Nickel Molybdenum alloy steel.

It is because of presence of more amount of Molybdenum in EN 29. The addition of Molybdenum improves hardenability, ductility, toughness, and elevated temperature properties of the steel and also Molybdenum inhibits grain growth and makes the steel less susceptible to temper brittleness.

\subsection{Optimization of Induction Hardening Process Variables}

Cause and Effect Analysis is made and Shewerts' diagram (Fig. 13) is drawn for the Induction hardening process. From this, the major contributing process variables have been identified.

Analysis of variance is done for AISI 4340, AISI 1055. The ANOVA results, and F-Test results (Tables 16, 17, 2023) shows that Power potential has more influence on the hardness and case depth of the Induction hardened components. This matches with the suggestion given by Mehmet Cengiz Kayacan and Oguz Colak 2004. In order to obtain the significance and effect of each factor and their interaction, the sum of the squares, Degrees of freedom, Mean square and $\mathrm{F}$ are calculated first. Based on these calculations the Ranking and significance of each variable are done [23-24]. F-Test ranking also shows that Power potential is the number one variable having effect on surface hardness and case depth [25].

Figs. (9a-c, 11a-c) shows that under optimal conditions (Power potential $5.5 \mathrm{~kW} /$ inch $^{2}$, Scan speed $1.72 \mathrm{~m} /$ minutes and Quench flow rate 15 litres/min) the hardness and case depth is maximum for the materials AISI 4340 and AISI 1055 with low distortion.

In the present experimental analysis, optimum induction hardening conditions to obtain high hardness and with low distortion is given in Table $\mathbf{2 6}$.

Regression analysis is done and the controlling equation to predict the Hardness and Case depth of Induction hardened components at any parametric conditions has been developed [26]. To check the Regression equations confirmation trials are carried out and the results are tabulated in Table 27. It shows that there is a good match between the experimental results and predicted regression results.

\section{CONCLUDING REMARKS}

- $\quad$ Furnace Temperature and Quenching time have equal influence on the Surface integrity of the case hardened components in Gas Carburizing. The investigation reveals that the interaction effect 


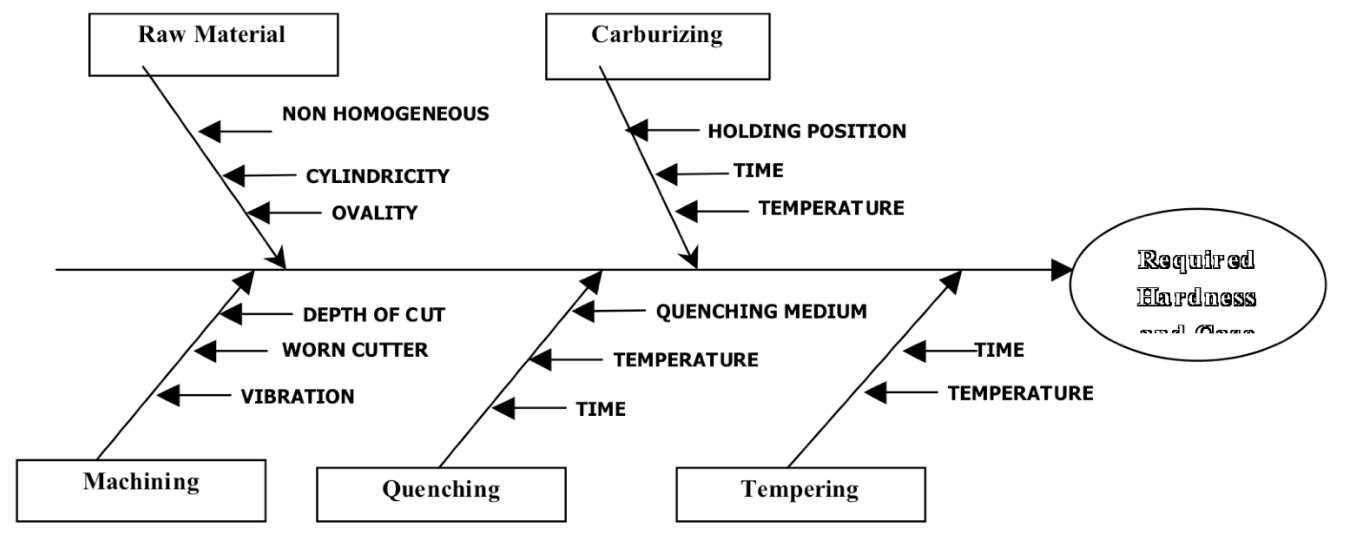

Fig. (12). Shewerts' diagram for Gas carburizing process.

between Furnace Temperature and Quenching time is $30 \%$.

- Optimum Gas Carburizing Process conditions as per the present test results to obtain Higher surface hardness with more case depth are,
Table 24. Optimum Gas Carburising Process Conditions

\begin{tabular}{|c|c|c|}
\hline S. No. & Process Variables & Values with Unit \\
\hline \hline 01 & Furnace Temperature & $940^{\circ} \mathrm{C}$ \\
\hline 02 & Quenching Time & 90 Minutes \\
\hline 03 & Tempering Temperature & $200^{\circ} \mathrm{C}$ \\
\hline 04 & Tempering Time & 120 Minutes \\
\hline
\end{tabular}

Table 25. Experimental Trials vs Predicted Values by Taguchis' DOE

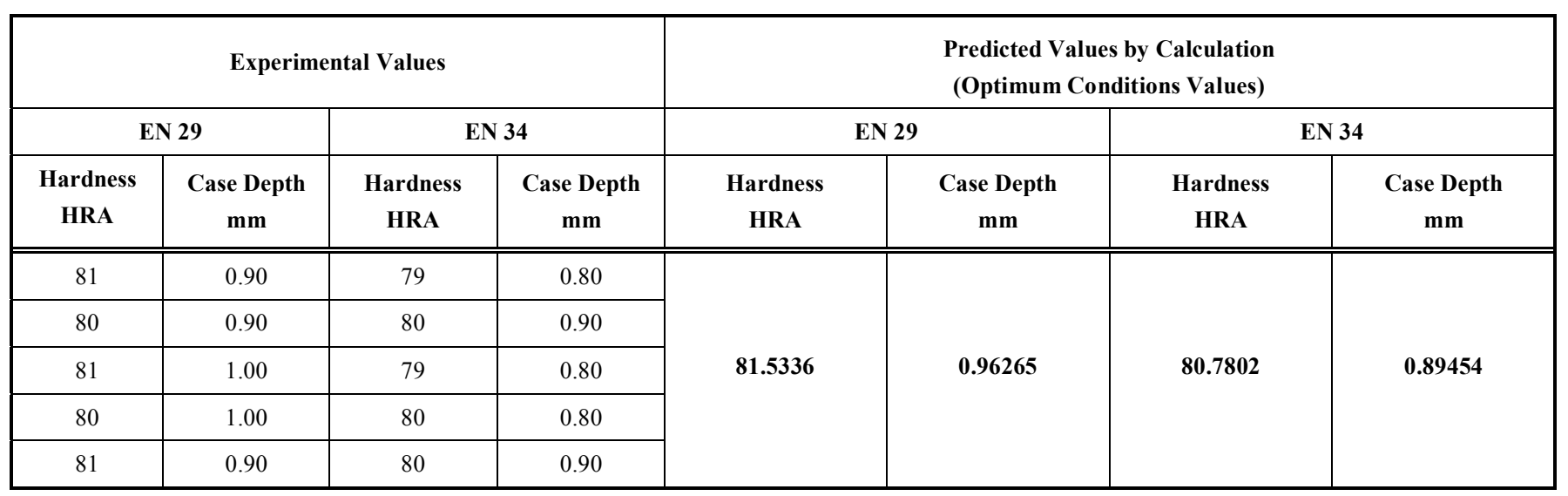

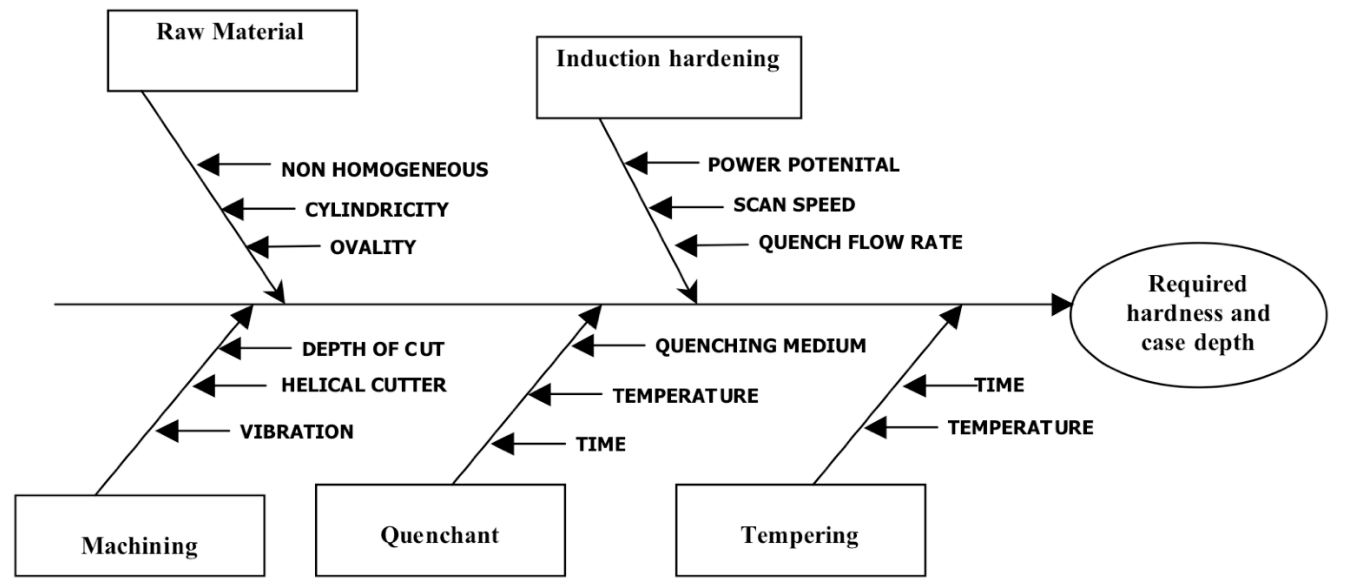

Fig. (13). Shewerts' diagram for Induction hardening process. 
Table 26. Optimum Induction Hardening Process Conditions

\begin{tabular}{|c|c|c|}
\hline S. No. & Process Variables & Values with Unit \\
\hline \hline 01 & Power Potential & $5.5 \mathrm{~kW} /$ inch $^{2}$ \\
\hline 02 & Scan Speed & $1.72 \mathrm{~m} /$ minutes \\
\hline 03 & Quench Flow rate & $15 \mathrm{Litres} /$ minutes \\
\hline 04 & Frequency & $10 \mathrm{kHz}$ \\
\hline
\end{tabular}

- In the present experimental analysis, optimum induction hardening conditions to obtain high hardness and with low distortion are,

- $\quad$ The Controlling equations developed through Regression Analysis are useful in fixing the parameters at the required level.

\section{ACKNOWLEDGEMENTS}

The authors are thankful to Rane (Madras) Pvt. Ltd., Thirubhuvanai, Pondicherry and IGCAR Kalpakkam for providing the experimental, testing and measurement facilities.

Table 27. Confirmation Trials Results vs Predicted Optimum Results

\begin{tabular}{|c|c|c|c|c|c|c|c|c|c|c|c|}
\hline \multirow[t]{2}{*}{ Trials } & \multicolumn{3}{|c|}{ Experimental Conditions } & \multicolumn{2}{|c|}{ Hardness in HRA } & \multicolumn{2}{|c|}{ Distortion in mm } & \multicolumn{2}{|c|}{$\begin{array}{l}\text { Case Depth Below } \\
\text { the Teeth in } \mathrm{mm}\end{array}$} & \multicolumn{2}{|c|}{$\begin{array}{l}\text { Case Depth Back } \\
\text { of the Bar in } \mathbf{m m}\end{array}$} \\
\hline & $\mathbf{P}$ & $\mathbf{S}$ & $\mathbf{Q}$ & $\mathbf{a}$ & b & $\mathbf{a}$ & b & $\mathbf{a}$ & b & $\mathbf{a}$ & b \\
\hline 01 & 4.5 & 1.30 & 10.0 & 87.0 & 85.0 & 2.04 & 2.50 & 2.70 & 2.5 & 4.40 & 4.40 \\
\hline 02 & 5.0 & 1.5 & 12.5 & 83.7 & 82.0 & 1.74 & 1.95 & 2.45 & 2.2 & 3.91 & 3.50 \\
\hline $\mathbf{0 3}$ & 5.5 & 1.72 & 15.0 & 80.4 & 79.0 & 1.43 & 1.50 & 2.20 & 2.0 & 3.42 & 3.30 \\
\hline 04 & 6.0 & 2.0 & 18.0 & 76.8 & 76.0 & 1.08 & 1.00 & 1.92 & 1.8 & 2.88 & 2.50 \\
\hline
\end{tabular}

$\mathrm{a}-$ Predicted values from Regression equation; $\mathrm{b}$ - Confirmation trials values.

Table 7.1. Optimum Conditions for Gas Carburizing Process

\begin{tabular}{|c|c|c|}
\hline S. No. & Process Variables & Values with Unit \\
\hline \hline 01 & Furnace Temperature & $940^{\circ} \mathrm{C}$ \\
\hline 02 & Quenching Time & 90 Minutes \\
\hline 03 & Tempering Temperature & $200^{\circ} \mathrm{C}$ \\
\hline 04 & Tempering Time & 120 Minutes \\
\hline
\end{tabular}

Table 7.2. Optimum Conditions for Induction Hardening Process

\begin{tabular}{|c|c|c|}
\hline S. No. & Process Variables & Values with Unit \\
\hline \hline 01 & Power Potential & $5.5 \mathrm{~kW} /$ inch $^{2}$ \\
\hline 02 & Scan Speed & $1.72 \mathrm{~m} /$ minutes $^{2}$ \\
\hline 03 & Quench Flow rate & $15 \mathrm{Litres} / \mathrm{minutes}$ \\
\hline 04 & Frequency & $10 \mathrm{kHz}$ \\
\hline
\end{tabular}

- $\quad$ Preheating before Gas Carburizing increases the obtainable hardness and case depth of the material. It holds good with the remarks given by Shen-Chih Lee and Wei -Youe Ho(1989) on their paper "The effects of surface hardening on Fracture Toughness of Carburized steel".

- $\quad$ Power Potential has major influence on the Surface Hardness and Case depth of the Induction hardened components. This matches with the suggestion given by Mehmet Cengiz Kayacan and Oguz Colak 2004 [27].

\section{REFERENCES}

[1] Alford LP, Beatty HR. Principles of industrial management. Ronald P: US 1951.

[2] Grossmann MA, Bain EC. Principles of heat treatment. Hetenyi M, Ed. ASM. Ohio: Cleveland 1964.

[3] American Iron and Steel Institute. Steel products manual tool steels 1976.

[4] Schimizu N, Tamura I. An examination of the relation between quench-hardening behaviour of steel and cooling curve in oil. Trans ISIJ 1978; 18: 445-50.

[5] Barbacki A, Mikolajski E. Optimization of heat treatment conditions for maximum toughness of high strength silicon steel. Int J Mater Process Technol 1998; 78: 18-23.

[6] Fee AR, Robert, Edward SL. Mechanical testing of materials. ASMHandbook 1995; vol. 8: pp. 91-3.

[7] Arkhipov YAJ, Batyrev VA, Polotskii MS. internal oxidation during carburizing and heat treating. Metals Trans A 1972; 9A(11): 1553-60.

[8] ASM metals handbook: heat treating. $9^{\text {th }}$ ed. Ohio: Metal Park 1981; vol. 4.

[9] Montgomery DC. Introduction to statistical quality control. Singapore: John Wiley and Sons (ASIA) Pte Ltd. 2001.

[10] Singh H, Kumar P. Tool wear optimization in turning operation by Taguchi method. Indian J Eng Mater Sci 2004: 11; 19-24

[11] Harris FE. Case Depth - An attempt at practical definition. Metal Prog 1943

[12] Rajan TV, Sharma CP, Sharma A. Heat treatment principles and techniques. $8^{\text {th }}$ ed. India: Prentice-Hall of (India) Pvt. Ltd. 1985.

[13] Brooks CR. Principles of heat treatment of plain carbon and low alloy steels. ASM International, Ohio: Metal Park 1996.

[14] Osborn HB. Surface hardening by induction heat. Metal Prog 1955; pp. 105-9.

[15] Scott Mackenzie D. Principles of quenching for induction hardening, presented at the SME induction hardening seminar, Michigan, $15^{\text {th }}$ May 2002, Nov 2002; pp.1-10.

[16] Bodart O, Boureau AV, Touzani R. Numerical investigation of optimal control of induction heating processes. Int J Appl Math Model 2001; 25: 697-712.

[17] Dughiero F, Battistetti M. Optimization procedures in the design of continuous induction hardening and tempering installations for magnetic steel bars. IEEE Trans Magnet 1998; 34: 2865-8. 
[18] Ashby MF, Easterling KE. The transformation hardening of steel surfaces by laser beams -I Hypo -eutectoid Steels. Acta Metall 1984; 32(A11): 1935-48.

[19] Averbach BL, Cohen, Fletcher's. The dimensional stability of steel -part-iii, decomposition of martensite and austenite at room temperature. Trans ASM 1948; 40: 726-8.

[20] Fischer FD. Simplified calculation of temperature filed in heat treated cylinder using temperature measured at one point. Mater Sci Technol 1992; 1; 468-73.

[21] Iozinskii MG. Industrial application of induction heating. Oxford Pregamon Press Ltd 1969.
[22] Lee SC, Ho WY. The effects of surface hardening on fracture toughness of carburized steel. Metall Trans A 1989; 20A: 519-24.

[23] Matsui K, Hata H, Kadogawa H, Yoshiyuki K. Research on practical application of dual frequency induction hardening to gears. Int J Soc Automot Eng 1998; 19: 351-71.

[24] Kayacan MC. Design and construction of a set-up for induction hardening, M. Sc., Thesis, University of Gaziantep 1991.

[25] Shary B, Osborn Jr. Surface hardening by induction. Cleveland: Park-Ohio Industries Inc. 1974: 181-3.

[26] Semiatin SL, Stutz DE. Industrial heat treatment of Steel 1986.

[27] Kayacan MC, Colak O. A fuzzy approach for induction hardening parameters selection. Int J Mater Des 2004: 25; 155-61.

(C) Palaniradja et al.; Licensee Bentham Open.

This is an open access article licensed under the terms of the Creative Commons Attribution Non-Commercial License (http://creativecommons.org/licenses/by-nc/ 3.0/) which permits unrestricted, non-commercial use, distribution and reproduction in any medium, provided the work is properly cited. 